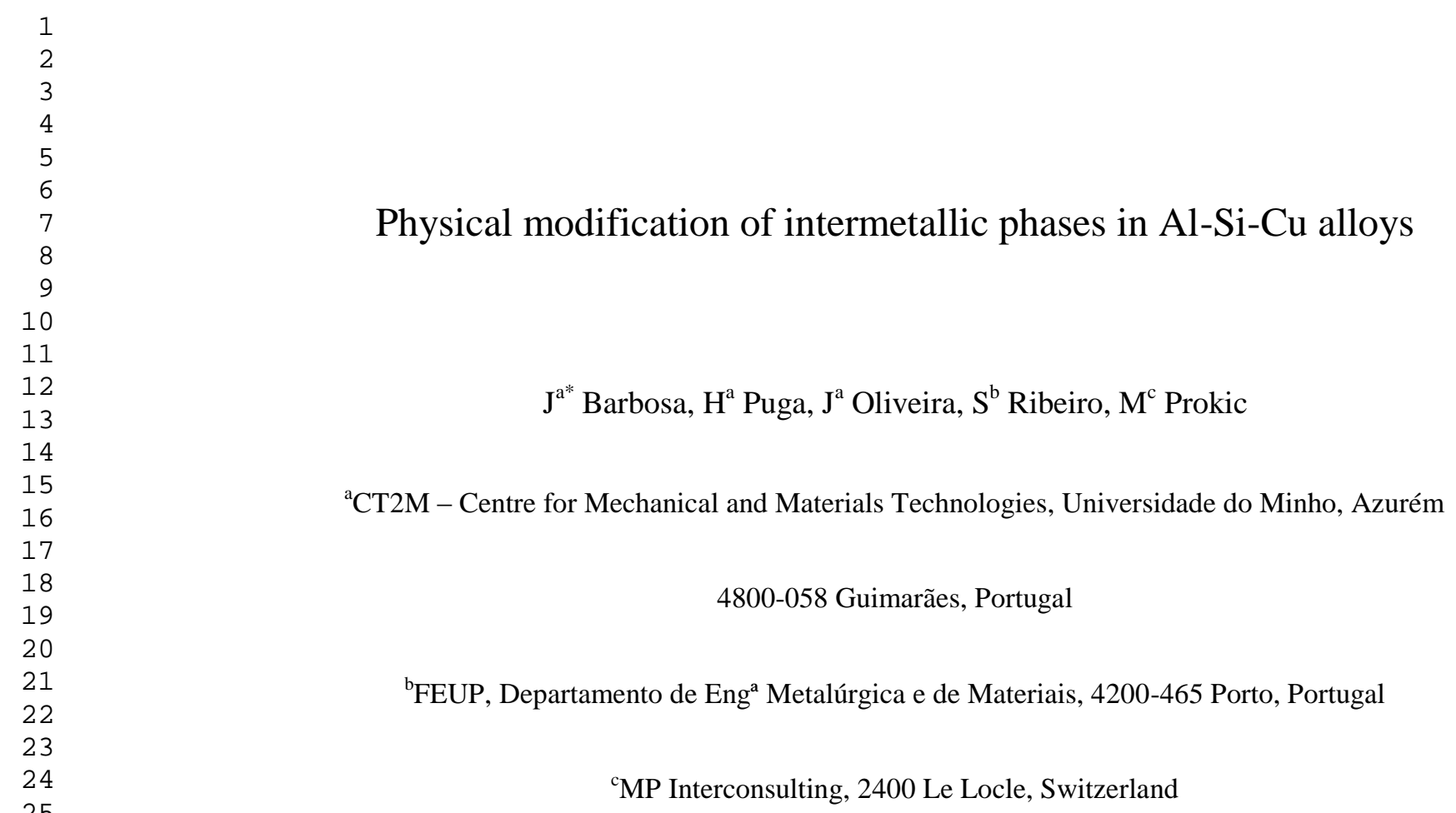

\section{Physical modification of intermetallic phases in Al-Si-Cu alloys}

\author{
$\mathrm{J}^{\mathrm{a}^{*}}$ Barbosa, $\mathrm{H}^{\mathrm{a}}$ Puga, $\mathrm{J}^{\mathrm{a}}$ Oliveira, $\mathrm{S}^{\mathrm{b}}$ Ribeiro, $\mathrm{M}^{\mathrm{c}}$ Prokic \\ ${ }^{\mathrm{a}} \mathrm{CT} 2 \mathrm{M}$ - Centre for Mechanical and Materials Technologies, Universidade do Minho, Azurém
}

4800-058 Guimarães, Portugal

${ }^{\mathrm{b}}$ FEUP, Departamento de Eng ${ }^{\mathrm{a}}$ Metalúrgica e de Materiais, 4200-465 Porto, Portugal

${ }^{\mathrm{c}}$ MP Interconsulting, 2400 Le Locle, Switzerland

*Corresponding author. Tel: +351253510220 ; Fax: +351253516007

E-mail address: kim@dem.uminho.pt (J. Barbosa) 


\section{Keywords}

Intermetallic compounds; Solidification; Electron microscopy; Microstructure; Nucleation 


\section{Introduction}

$\mathrm{Al}$-Si alloys are among the casting alloys most widely used in engineering applications mainly due to their excellent castability, lightweight and high strength, low thermal expansion and good corrosion resistance [1-3]. However, their mechanical properties are strongly affected by type, morphology and distribution of second phases, which depends on the chemical composition of the alloy and the solidification conditions [3]. Although silicon provides the necessary fluidity to feed metal shrinkage their eutectic morphology strongly affects the mechanical properties of the alloys. In slow solidification conditions the eutectic silicon presents an acicular morphology which decreases the mechanical properties of the alloys, particularly tensile strength and ductility [4]. Thus, modification of eutectic silicon structure it's usually required to improve the mechanical performance of the cast components.

The formation of complex intermetallic phases is mainly due to the presence of some impurities like iron, manganese, nickel or chromium in the composition of these alloys [5]. Iron is the most detrimental element for the mechanical properties since it possesses a low solid solubility in aluminium and tends to combine with other elements resulting in the formation of intermetallic compounds [5, 6]. These compounds can appear in a wide variety of shapes and are generally divided in three different morphologies, namely as thin needles or platelets, as Chinese script and polyhedral and/or star-like crystals [7, 8]. However, the composition and type of intermetallics highly dependent on the alloy composition and cooling conditions [9].

Thin needles appear as monoclinic $\beta-\mathrm{Al}_{5} \mathrm{FeSi}$ under solidification conditions normally used in foundry and are the most harmful phase for the mechanical properties since their sharp tips act as stress concentrators reducing the ductility and toughness of the material $[1,10,11] . \beta$-phase is hard and brittle and has low bond strength with the matrix $[10,12]$. Moreover this phase is formed at early stages of solidification which is detrimental to the melt fluidity and feeding action. Additionally $\beta$-phase has been related with the formation of shrinkage and gas porosity since these long needles can block the interdendritic feeding channels $[6,10,13]$. The length of the $\beta$ - $\mathrm{Al}_{5} \mathrm{FeSi}$ needles or platelets is strongly dependent on the iron content of the alloy and the cooling rate. Thus, with the increase of iron content or the decrease of cooling rates the size of $\beta$-needles tends to increase. However, with the increase of iron level the volume fraction of intermetallic compounds does not increase considerably $[12,13]$.

Since the presence of iron in Al-Si alloys is inevitable and removal is not cost affordable, its negative effect should be minimized by the transformation of $\beta$-phase to a more compact and less detrimental compound [7, 14] which can be achieved by superheating the melt, addition of sufficient level of manganese or by using high cooling rates $[1,7,12]$. The addition of Mn will neutralize the negative effect of iron by converting the formation of $\beta-\mathrm{Al}_{5} \mathrm{FeSi}$ to a phase with a more compact morphology. This phase is the cubic $\alpha-\mathrm{Al}_{15}(\mathrm{Fe}, \mathrm{Mn})_{3} \mathrm{Si}_{2}$ with Chinese script, polyhedral or star-like morphology, which is less harmful to the mechanical properties than the $\beta$ - $\mathrm{Al}_{5} \mathrm{FeSi}$ platelets $[6,7]$. For instance, in alloys with manganese the Fe/Mn ratio should be around 2:1 for an effective modification of the $\beta$-phase [1, 7]. Nevertheless, the addition of $\mathrm{Mn}$ also has some disadvantages, namely a tendency to increase the volume fraction and size of $\alpha$-phase which is also detrimental to the alloy properties $[6,15]$.

Furthermore, the presence of manganese in these alloys can be a problem since it may promote the crystallization of coarse $\alpha-\mathrm{Al}_{15}(\mathrm{Fe}, \mathrm{Mn})_{3} \mathrm{Si}_{2}$, usually called "sludge". These particles have high specific gravity, having high tendency to settle down on the furnace or crucible, leading to chemical composition 
heterogeneity of the melt $[6,16]$. Fluctuations in the melt temperature or holding it at a temperature just above liquidus can be the reasons that lead to the formation of those sludge particles [12]. Consequently, the addition of Mn must be just the necessary to modify the negative effect of iron rich platelets. In Mnfree or low-Mn content alloys, alternative routes like high cooling rates can be used to avoid the formation of $\beta$-phase, promoting the formation of hexagonal $\alpha-\mathrm{Al}_{8} \mathrm{Fe}_{2} \mathrm{Si}$ with skeleton-like morphology [2, $7,17]$. Other phases such as $\alpha-\mathrm{Al}_{19}(\mathrm{Fe}, \mathrm{Mn})_{5} \mathrm{Si}_{2}, \delta-\mathrm{Al}_{4} \mathrm{FeSi}_{2}$ and $\alpha-\mathrm{Al}_{8}(\mathrm{Fe}, \mathrm{Mn})_{2} \mathrm{Si}$ have also been identified in Al-Si alloys $[18,19]$. The presence of magnesium in these alloys can promote the formation of other intermetallic compound named $\pi-\mathrm{Al}_{8} \mathrm{FeMg}_{3} \mathrm{Si}_{6}$ phase, that presents a scrip-like morphology and in some cases is connected to the $\beta$-phase [2].

Recently, ultrasonic vibration has been used to improve castings quality by promoting melt degassing [20] and the formation of non-dendritic and globular $\alpha$-Al grains in $\mathrm{Al}-\mathrm{Si}$ alloys and modification of the eutectic silicon particles [21-23]. It has also been reported that ultrasonic treatment modified the morphology of intermetallic compounds by converting the plates of $\beta$-phase to a fine polyhedral morphology [16] or changing the morphology of $\beta$-phase needles to refined Chinese script shaped compounds [22] in hypoeutectic Al-Si alloys. Moreover, it has also been reported that ultrasound can promote the formation and refinement of $\delta$-phase instead of $\beta$-phase in hypereutectic Al-Si alloys [19]. Nevertheless, the application of this technique for the modification of complex intermetallics compounds is not well reported.

In this article the microstructure of a hypoeutectic $\mathrm{Al}-\mathrm{Si}-\mathrm{Cu}-(\mathrm{Fe})$ alloy was analysed by Optical Microscopy, SEM/EDS and XRD in order to study the effect of ultrasonic treatment in the size, morphology and nucleation mechanism of the phases formed during solidification, namely $\alpha$-Al grains, complex intermetallic compounds and the eutectic Si particles.

\section{Experimental Procedure}

\subsection{Materials and Melting}

Table 1 shows the composition of the AlSi9Cu3(Fe) alloy used on this work, obtained by Optical Emission Spectrometry.

Table 1. Composition of the AlSi9Cu3 alloy used in this work.

\begin{tabular}{c|c|c|c|c|c|c|c}
\hline Element & Si & Fe & Mg & Cu & Mn & Zn & Al \\
\hline Wt\% & 9.15 & 0.66 & 0.18 & 2.25 & 0.26 & 0.47 & Bal. \\
\hline
\end{tabular}

\subsection{Experimental set-up}

The experimental set-up (Fig. 1) used in this work consisted of a novel MMM (Multi-frequency, Multimode, Modulated technology) ultrasonic power supply unit, a high power ultrasonic converter $(1200 \mathrm{~W})$, a $30 \mathrm{~mm}$ diameter and $150 \mathrm{~mm}$ long acoustic waveguide and the acoustic load itself which consisted on a $20 \mathrm{~mm}$ diameter and $75 \mathrm{~mm}$ long $\mathrm{Nb}$ acoustic radiator and the liquid metal. 
The alloy $(0.2 \mathrm{~kg})$ was melted and held inside the crucible at $700^{\circ} \mathrm{C}$ during $15 \mathrm{~min}$ for homogenization. The molten alloy was then poured into a steel die with $40 \mathrm{~mm}$ diameter and $120 \mathrm{~mm}$ height. The die was preheated at $300^{\circ} \mathrm{C}$ and US vibration was applied continually directly to the melt on two different conditions: (1) US vibration until $618 \pm 2^{\circ} \mathrm{C}$ (liquidus temperature); (2) US vibration until $580 \pm 2^{\circ} \mathrm{C}$ (solidus temperature). After vibration, the melt cooled until room temperature inside the die. Ultrasonic frequency of $20.3 \pm 0.25 \mathrm{kHz}$ at $30 \%$ electric power were used for each processing condition. For the sake of comparison experiments were also carried out without US vibration.

\subsection{Microstructural characterization}

Samples for microstructural characterization were taken from each cast sample by sectioning them perpendicularly to its longitudinal axis at a distance to the acoustic radiator of $40 \mathrm{~mm}$ (Fig. 1). The samples were ground with $\mathrm{SiC}$ paper, polished down to $0.025 \mu \mathrm{m}$ with non-crystallized colloidal silica and etched with Dix-Keller reagent, to observe more clearly their microstructure. In order to reveal a 3D like morphology of the intermetallic compounds and $\mathrm{Cu}$ rich phases, the samples were deeply etched in $37 \%$ $\mathrm{HCl}$ solution during 15 second.

The overall microstructure morphology was analysed by optical microscopy using a Leica DM 2500 M. Detailed analysis of intermetallic compounds morphology and chemical composition was done using a NanoSEM - FEI Nova 200 (FEG/SEM) scanning electron microscope equipped with an energy dispersive spectrometer EDAX - Pegasus X4M, operating at an accelerating voltage of $15 \mathrm{keV}$ and 70 seconds of acquisition time. Identification of each phase was complemented with XRD analysis carried out on a Bruker AXS diffractometer equipped with $\mathrm{Cu}-\alpha$ radiation source. Image Pro Plus software was used to quantify the average grain size and volume fraction of constituents. 


\section{Results and Discussion}

\subsection{Effect of ultrasonic vibration on the microstructure of AlSi9Cu3 alloy}

The effect ultrasonic vibration on the microstructure was the first issue studied in this work. Fig. 2(a) shows the microstructure of as-cast samples and Fig. 2(b) the microstructure of the sample US treated until $618 \pm 2^{\circ} \mathrm{C}$. The as-cast sample has a dendritic structure while the US treated sample has a more globular one, revealing that the application of acoustic energy during solidification promotes the formation of globular $\alpha$ - $\mathrm{Al}$ grains with average size of $65 \pm 3 \mu \mathrm{m}$, improving the mechanical properties of the alloy. These results are consistent with those obtained by Puga et al. [22], who verified that US treatment changes the structure of primary aluminium, decrease their average grain size and improves the mechanical properties. The decrease in grain size can be explained by the cavitation-enhanced mechanism promoted by the application of acoustic energy to the molten metal. In the first stage of the solidification occurs the formation of cavitation bubbles, which increase the nucleation rate. These bubbles grow and finally collapse, causing acoustic streaming that disperse the nuclei previously formed throughout the melt, promoting the occurrence of heterogeneous nucleation sites [22, 24].

Although it is not perceptible in Figs. 2(a) and 2(b) due to its low magnification, the type and morphology of Fe-containing intermetallics are different on each sample. While in as-cast sample they appear more frequently as thin needles or coarse platelets, or less commonly with Chinese script shape morphology, in the US treated samples they appear as hexagonal crystals. The morphology and the mechanisms that lead to those different morphologies are presented and discussed in detail on the next section.
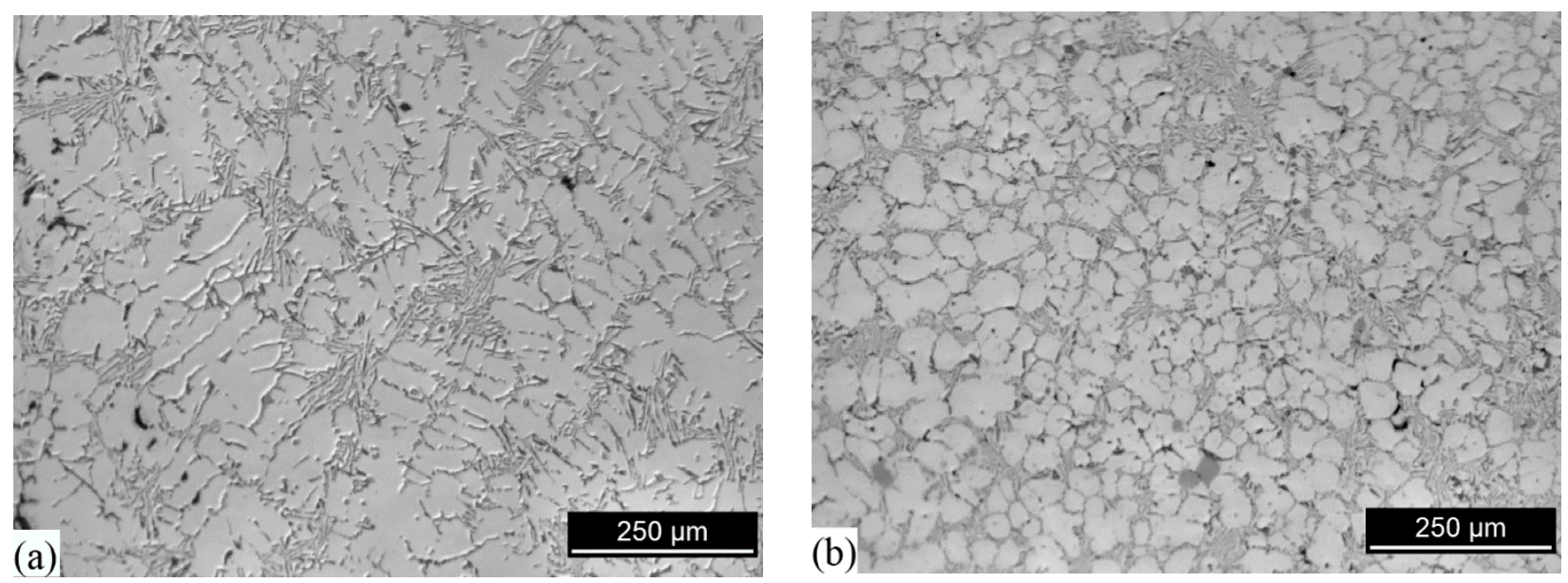

Fig. 2. Optical micrographs for $\mathrm{AlSi}_{9} \mathrm{Cu}_{3}(\mathrm{Fe})$ samples obtained in a steel mould, preheated at $250^{\circ} \mathrm{C}$, in different processing conditions. (a) As-cast sample; (b) Sample US treated until $618 \pm 2^{\circ} \mathrm{C}$.

\subsection{Effect of ultrasonic vibration on the composition and morphology of intermetallic phases}

\subsubsection{Samples without US treatment}

Fig. 3 shows the microstructure of the as-cast sample. Besides $\alpha$-Al and eutetic Si plates, SEM analysis revealed the presence of different intermetallic phases, which morphology (Fig. 3) and chemical analysis (Table 2) suggest to be the well-known $\beta$-phase (Z1) with needle like morphology, the "Chinese script" 
shaped $\alpha$-phase (Z2) and eutectic $\mathrm{Al}_{2} \mathrm{Cu}(\mathrm{Z3})$. These phases are not uniformly distributed in the matrix, suggesting that strong chemical segregation occurred during solidification. These results are consistent with those obtained by Narayanan et al. [12] who verified, in the 319 alloy, that in the presence of manganese and for high cooling rates almost $50 \%$ of the iron present in the alloy crystalizes in the form of $\beta$-phase.
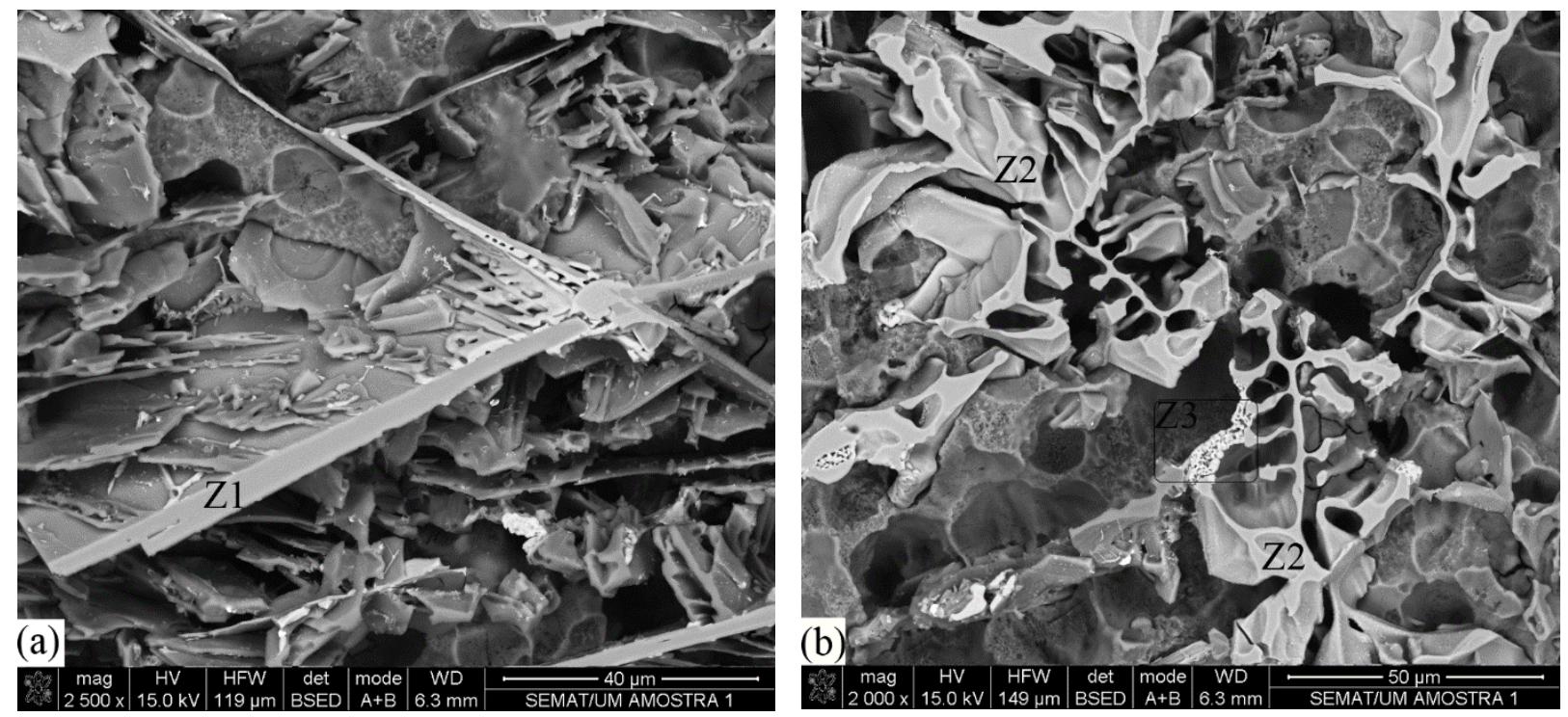

Fig. 3. SEM image of deeply etched samples showing the morphology of complex intermetallic compounds present in as-cast sample. (a) Platelet like intermetallics (Z1); (b) Chinese script like intermetallics (Z2) and eutectic $\mathrm{Al}_{2} \mathrm{Cu}$ (Z3).

Table 2 - Chemical composition of intermetallic phases detected on the as-cast AlSi9Cu3 alloy produced without treatment with acoustic energy, corresponding to phases Z1, Z2 and Z3 indicated in Fig. 3.

\begin{tabular}{c|c|c|c|c|c}
\hline \multirow{2}{*}{ Constituent } & \multicolumn{5}{|c}{ Composition (at \%) } \\
\cline { 2 - 6 } & $\mathrm{Al}$ & $\mathrm{Si}$ & $\mathrm{Fe}$ & $\mathrm{Cu}$ & $\mathrm{Mn}$ \\
\hline $\mathrm{Z} 1$ & 69.8 & 13.3 & 14.9 & - & - \\
\hline $\mathrm{Z} 2$ & 71.8 & 11.7 & 11.6 & - & 4.5 \\
\hline $\mathrm{Z} 3$ & 53.2 & - & - & 46.8 & - \\
\hline
\end{tabular}

$\mathrm{XRD}$ analysis was carried out to confirm EDS results and to identify accurately the intermetallic phases in the cast samples (Fig.4). The XRD spectrum of the non Us treated sample reveals the presence of $\alpha$ $\mathrm{Al}_{17}\left(\mathrm{Fe}_{3.2}, \mathrm{Mn}_{0.8}\right) \mathrm{Si}_{2}, \alpha-\mathrm{Al}_{8} \mathrm{Fe}_{2} \mathrm{Si}, \beta-\mathrm{Al}_{9} \mathrm{Fe}_{2} \mathrm{Si}_{2}$ and $\mathrm{Al}_{2} \mathrm{Cu}$ intermetallic phases. The $\alpha-\mathrm{Al}_{8} \mathrm{Fe}_{2} \mathrm{Si}$ phase only forms in the absence of Mn or in alloys with very low Mn content, as reported by Ji et al. [25]. The presence of this phase in the as-cast alloy can be explained by the heterogeneity of the melt composition, with absence of $\mathrm{Mn}$ in some melt regions where this phase could form. The $\alpha-\mathrm{Al}_{17}\left(\mathrm{Fe}_{3.2}, \mathrm{Mn}_{0.8}\right) \mathrm{Si}_{2}$ phase has a cubic structure, with space group $P m-3$ and lattice parameter $a=1.256 \mathrm{~nm}$. The $\beta-\mathrm{Al}_{9} \mathrm{Fe}_{2} \mathrm{Si}_{2}$ phase that exists in the as-cast samples has a monoclinic face-centered structure and presents space group $C 2 / c$ 
and lattice parameter $a=2.08 \mathrm{~nm}, b=c=0.616 \mathrm{~nm}$ and $\beta=90,72^{\circ}$. This phase corresponds to $\beta-\mathrm{Al}_{4.5} \mathrm{FeSi}$ that was studied by Hansen et al. [26] and have the same lattice parameters and space group than the $\beta$ $\mathrm{Al}_{9} \mathrm{Fe}_{2} \mathrm{Si}_{2}$ analysed in this work. The $\alpha-\mathrm{Al}_{8} \mathrm{Fe}_{2} \mathrm{Si}$ phase possesses hexagonal structure, space group $\mathrm{P}_{3} / m m c$ and lattice parameters $a=1.24 \mathrm{~nm}$ and $c=2.623 \mathrm{~nm}$. This phase is consistent with the phase verified by Roger et al. [27] who obtained the same lattice parameters for the phase $\mathrm{Al}_{7.1} \mathrm{Fe}_{2} \mathrm{Si}$.

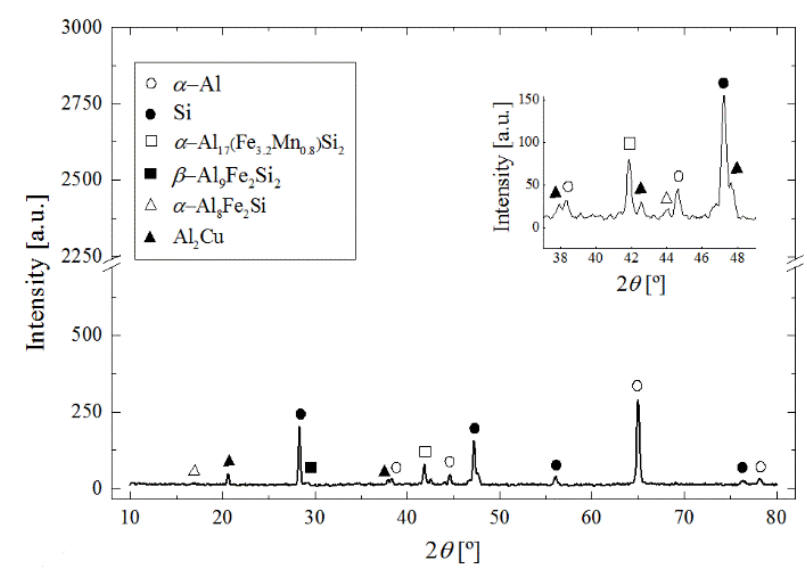

Fig. 4. X-ray diffraction spectrum of the sample obtained without US treatment, revealing the co-existence of $\alpha$-Al, $\mathrm{Si}, \mathrm{Al}_{17}\left(\mathrm{Fe}_{3.2}, \mathrm{Mn}_{0.8}\right) \mathrm{Si}_{2}, \alpha-\mathrm{Al}_{8} \mathrm{Fe}_{2} \mathrm{Si}, \beta-\mathrm{Al}_{9} \mathrm{Fe}_{2} \mathrm{Si}_{2}$ and $\mathrm{Al}_{2} \mathrm{Cu}$ phases.

Figs. 3(a) and 3(b) show the microstructure of the same sample after deeply etching with $\mathrm{HCl}$ solution to better reveal the morphologies of the $\beta$-phase and the Chinese script shaped $\alpha$-phase. The $\beta$-phase that appears as thin needles in cross section has, in fact, a platelet-like morphology, as reported by several authors [12]. Fig. 5 shows the morphology of the $\beta$-platelets with lower magnification. It is clear that these platelets are interconnected and can form a complex network that can be damaging for the mechanical properties of the as-cast parts. This result is consistent with those reported by Dinnis et al. [17], who observed that $\beta$-platelets form an interconnected and complex network, and this network is formed by the branching of individual platelets. The same author also verified that $\beta$-platelets can continue to growth even after an intersection point occurred, as it can also be observed in Fig. 5. The intermetallic $\alpha$-phase forms after $\alpha-\mathrm{Al}$ dendrites begin to solidify and both two phases form a coupled eutectic [17], which means that the intermetallic crystalizes in the $\alpha$-Al dendrites, as it can be seen in Fig. 3(b). 
Fig. 5. SEM image of $\beta$-phase platelets and Chinese script shaped $\alpha$-phase, showing that $\beta$-platelets continue to growth even after an intersection point occurred.

The simultaneous formation of $\alpha$ and $\beta$-phases in the as-cast sample can be explained by the theory proposed by Backerud et al. [28]. A schematic representation of the process is presented in Fig. 6. In normal solidification conditions the first phase to form is the primary dendritic $\alpha$-Al (path 1) while the interdendritic melt is enriching in iron and silicon. With the course of solidification, the segregation line enters in the $\alpha-\mathrm{Al}_{15}(\mathrm{Fe}, \mathrm{Mn})_{3} \mathrm{Si}_{2}$ domain and this phase starts to crystalize (path 2). As solidification proceeds, $\mathrm{Mn}$ is consumed until the interface between $\alpha-\mathrm{Al}_{15}(\mathrm{Fe}, \mathrm{Mn})_{3} \mathrm{Si}_{2}$ and $\beta-\mathrm{Al}_{5} \mathrm{FeSi}$ is reached. At this point, both phases crystallize simultaneously (path 3) until reaching the eutectic composition. In path 4 aluminium, silicon and $\beta$ phase crystallize together. When high cooling rates are used, only a fraction of the iron present in the alloy is consumed in path 2, and the remaining is available to form a mixture of $\alpha$ and $\beta$ phases through path 3 .

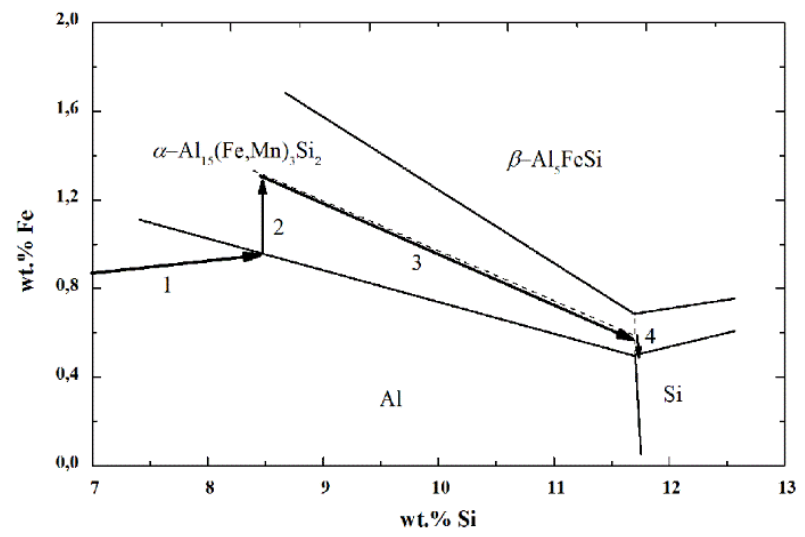

Fig. 6. Scheme of solidification process of an Al-Si-Cu alloy with 0.25\%wt. Mn [28]. 


\subsubsection{Samples with US treatment}

Figs. 7(a) and (b) show the microstructure of the sample US treated until $618 \pm 2^{\circ} \mathrm{C}$ and $580 \pm 2^{\circ} \mathrm{C}$, respectively. The intermetallic particles appear as hexagonal crystals, which chemical composition (Table 3) and EDS spectrum (Fig. 8) were found to be similar to those of the intermetallic $\alpha$-phase present in the non-Us treated sample. The XRD spectrum of this sample (Fig. 9) reveals the presence of $\mathrm{Al}_{17}\left(\mathrm{Fe}_{3.2}, \mathrm{Mn}_{0.8}\right) \mathrm{Si}_{2}$ and $\mathrm{Al}_{2} \mathrm{Cu}$, but there is no evidence of the presence of the $\beta$-phase, which agrees with the SEM analysis. Moreover, XRD also confirms that although their morphology is different, the stoichiometry of the $\alpha$-phase is the same in as-cast and US treated samples. However, the average volume fraction of polyhedral intermetallics in the US treated sample (8\%) is higher than the average volume fraction of Chinese script shaped particles in the as-cast sample (6\%). This fact can be explained by the suppression of $\beta$-phase formation that left higher contents of iron and manganese available to form the polyhedral $\beta$-phase. $\alpha-\mathrm{Al}_{8} \mathrm{Fe}_{2} \mathrm{Si}$ phase was not detected in US treated samples since one of the effects of ultrasound is to promote the homogeneity of the liquid alloy.
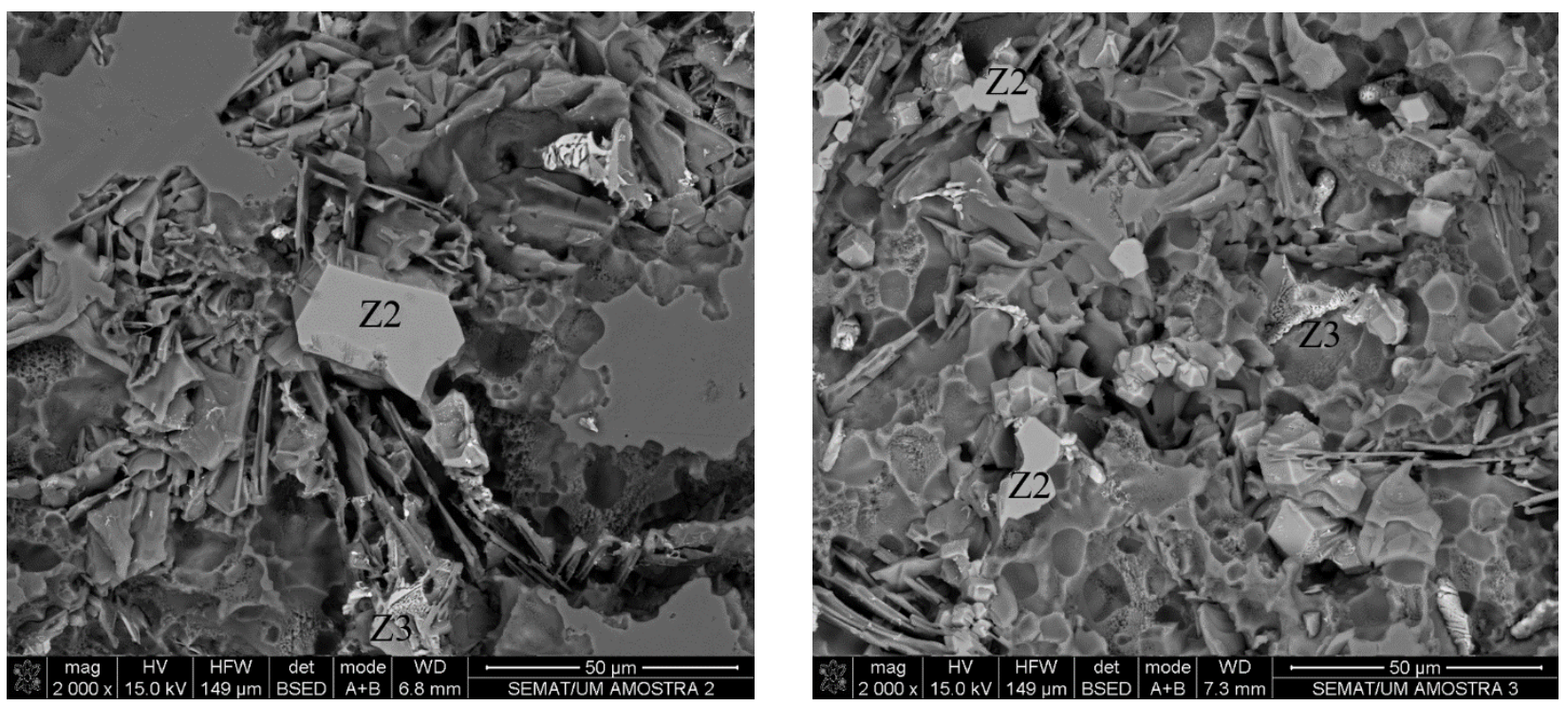

Fig. 7. SEM image showing the morphology of intermetallic compounds present in the sample US treated until (a) $618 \pm 2^{\circ} \mathrm{C}$ and (b) $580 \pm 2^{\circ} \mathrm{C}$

Table 3 - Chemical composition of intermetallic phases detected on the samples US treated until $580^{\circ} \mathrm{C}$, corresponding to phases Z2 and Z3 indicated in Fig. 7 (b).

\begin{tabular}{c|c|c|c|c|c}
\hline \multirow{2}{*}{ Constituent } & \multicolumn{5}{|c}{ Composition (at \%) } \\
\cline { 2 - 6 } & $\mathrm{Al}$ & $\mathrm{Si}$ & $\mathrm{Fe}$ & $\mathrm{Cu}$ & $\mathrm{Mn}$ \\
\hline $\mathrm{Z} 2$ & 74.4 & 12.6 & 9.5 & - & 3.5 \\
\hline $\mathrm{Z} 3$ & 57.3 & - & - & 42.7 & - \\
\hline
\end{tabular}


Fig. 8. EDS spectrum of the hexagonal shaped intermetallic compound present in the non US treated sample (identified as Z2 in Fig. 3 (b)) and in that US treated until $580^{\circ} \mathrm{C}$ (identified as Z2 in Fig. 7 (b)), suggesting that they are, in fact, the same phase.

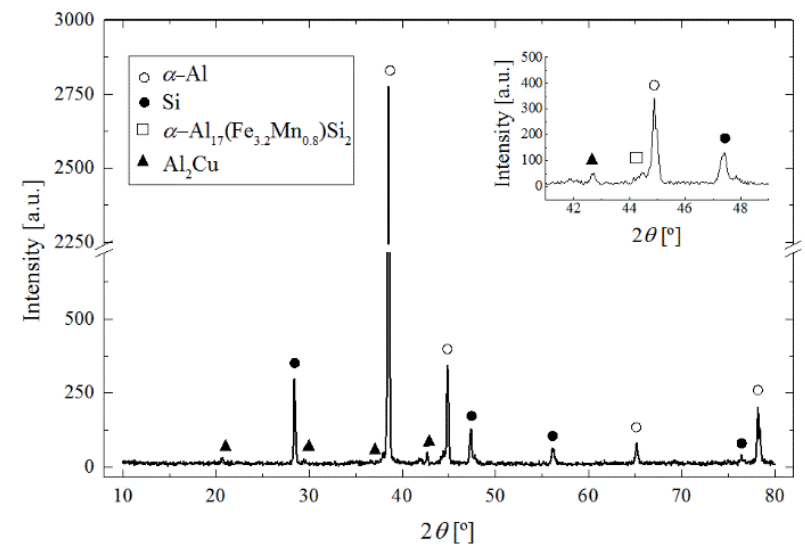

Fig. 9. X-ray diffraction spectrum of the sample US treated until $580^{\circ} \mathrm{C}$, revealing the co-existence of $\alpha-\mathrm{Al}, \mathrm{Si}$, $\mathrm{Al}_{17}\left(\mathrm{Fe}_{3.2}, \mathrm{Mn}_{0.8}\right) \mathrm{Si}_{2}$ and $\mathrm{Al}_{2} \mathrm{Cu}$ phases.

The presence $\mathrm{Al}_{2} \mathrm{Cu}$ with morphology and size similar to that of the as-cast sample is also present associated to the $\alpha$-phase. Thus, it's suggested that the application of acoustic energy changes the morphology of the $\alpha$-phase from Chinese script shape to polyhedral crystals. Moreover, the formation of $\beta$-phase is suppressed, which can be explained by the theory proposed by Narayanan et al. [12]: if almost all the iron is used in the crystallization of $\alpha$-phase before path 3 is attained, when the solidification range of $\beta$-phase is reached there is no iron available to form this phase, and its formation doesn't occur. In US treated samples, this can occur because ultrasonic vibration homogenizes the melt, avoiding or strongly decreasing chemical segregation. The presence of polyhedral crystals was already observed by Shabestari et al. [6], but in their study these crystals, namely the primary $\alpha-\mathrm{Al}_{12}(\mathrm{Fe}, \mathrm{Mn}, \mathrm{Cr})_{3} \mathrm{Si}_{2}$, appear both in nonmodified and Sr-modified alloy, and their morphology was attributed to the Mn content in the melt. A similar result was also reported by Khalifa et al. [16], who verified that the application of US melt 
treatment to $\mathrm{Al} 10 \mathrm{Si} 2 \mathrm{Cu}$ is effective converting the Fe-intermetallic particles to a more compact morphology, like polyhedral crystals with composition close to $\mathrm{Al}_{12}(\mathrm{Fe}, \mathrm{Mn}, \mathrm{Cr})_{2.9} \mathrm{Si}_{2}$.

By analysing the XRD spectra it's possible to observe that in the as-cast sample the more intense peak of $\alpha$-Al phase is located at $65.13^{\circ}$ while in the US treated samples it is located at $38.47^{\circ}$, meaning that this phase has a preferential orientation of grain growth according to the plan (220). In the US treated sample the $\mathrm{Al}$ grains grow in the plan (111). For the eutectic silicon the more intense peak is located at $28.44^{\circ}$ for both processing conditions, which means that this phase grows with a preferential orientation with the plan (111). This doesn't agree with the results obtained by Nogita et al. [29], who suggest that in unmodified alloys the eutectic silicon and the primary aluminium dendrites have the same orientation.

It has already been reported in literature that intermetallics can act as a nucleation sites for different phases formed during solidification. Fig. 3(a) suggests that $\beta$-platelets act as nucleation sites for the eutectic silicon. This was also verified by Shankar et al. [30], who refer that formation of $\beta-\mathrm{Al}_{5} \mathrm{FeSi}$ is associated to the silicon phase in hypereutectic alloys. It has also been reported that intermetallic compounds can also act as nucleation sites for the $\mathrm{Al}_{2} \mathrm{Cu}$ phase [31]. Fig. 10 shows the morphology of the $\mathrm{Al}_{2} \mathrm{Cu}$ phase present in the sample US treated until $618 \pm 2^{\circ} \mathrm{C}$. This phase occurs in a blocky form in both samples and since it is the last phase to solidify its nucleation is common to occur at the interfaces of other micro constituents already formed [32]. In the as-cast sample the $\mathrm{Al}_{2} \mathrm{Cu}$ phase nucleated in the eutectic silicon particles. However, in both US treated samples, it seems associated with the $\alpha$-phase intermetallics.

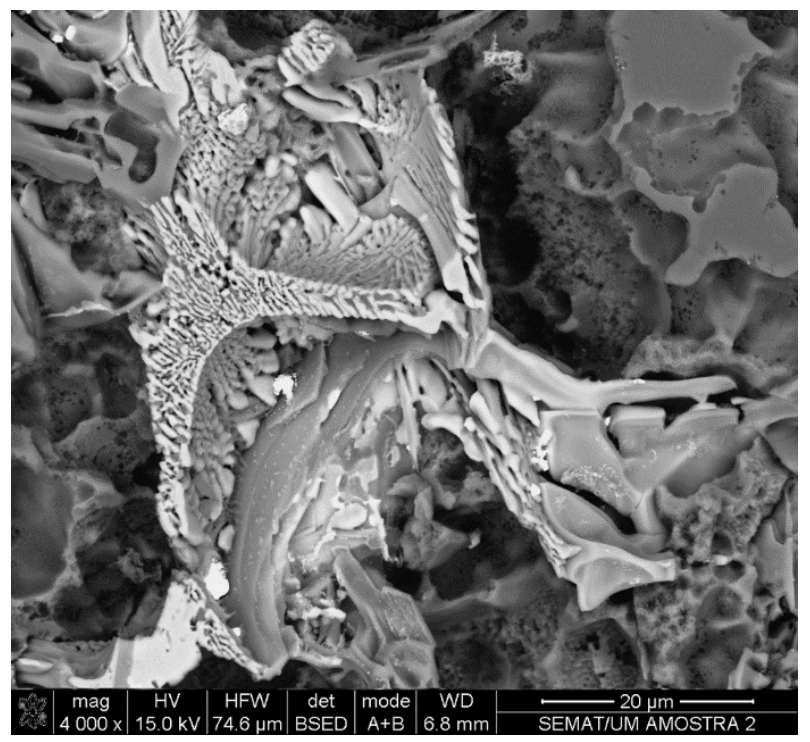

Fig. 10. SEM image of $\mathrm{Al}_{2} \mathrm{Cu}$ phase in the sample US treated until $618 \pm 2^{\circ} \mathrm{C}$.

\subsection{Effect of US treatment temperature range on the size of intermetallic phases}

Fig. 7 shows the morphology of intermetallic compounds formed in the samples ultrasonically treated at $618 \pm 2^{\circ} \mathrm{C}$ and $580 \pm 2^{\circ} \mathrm{C}$, respectively. It is clear that although the temperature range of US application has been different, their morphology is the same in both samples. According to the presented results it is plausible that the mechanism of cavitation promoted refinement of the intermetallic phases by 
heterogeneous nucleation. The $\alpha-\mathrm{Al}_{17}\left(\mathrm{Fe}_{3.2} \mathrm{Mn}_{0.8}\right) \mathrm{Si}_{2}$ phase present a blocky, polyhedral structure that appears as hexagonal crystals in the SEM image. The main difference between both samples concerns to the intermetallics size and distribution, which are smaller and more dispersed in the matrix on the sample US treated until lower temperature (average size of $10 \mu \mathrm{m}$ and $4 \mu \mathrm{m}$, respectively).

Fig. 11 shows the morphology of the $\alpha-\mathrm{Al}_{17}\left(\mathrm{Fe}_{3.2} \mathrm{Mn}_{0.8}\right) \mathrm{Si}_{2}$ phase of the same samples present in Fig.7 with higher magnification. It is clear that $\alpha-\mathrm{Al}_{17}\left(\mathrm{Fe}_{3.2} \mathrm{Mn}_{0.8}\right) \mathrm{Si}_{2}$ appear as coupled polyhedral crystals, which are much smaller in the sample treated until $580^{\circ} \mathrm{C}$. The most probable explanation for the difference in size is the fragmentation of the crystals after forming caused by the ultrasonic vibration, as suggested by the fracture lines present in the image of the sample US treated until $618 \pm 2^{\circ} \mathrm{C}$ shown in Fig. 12.
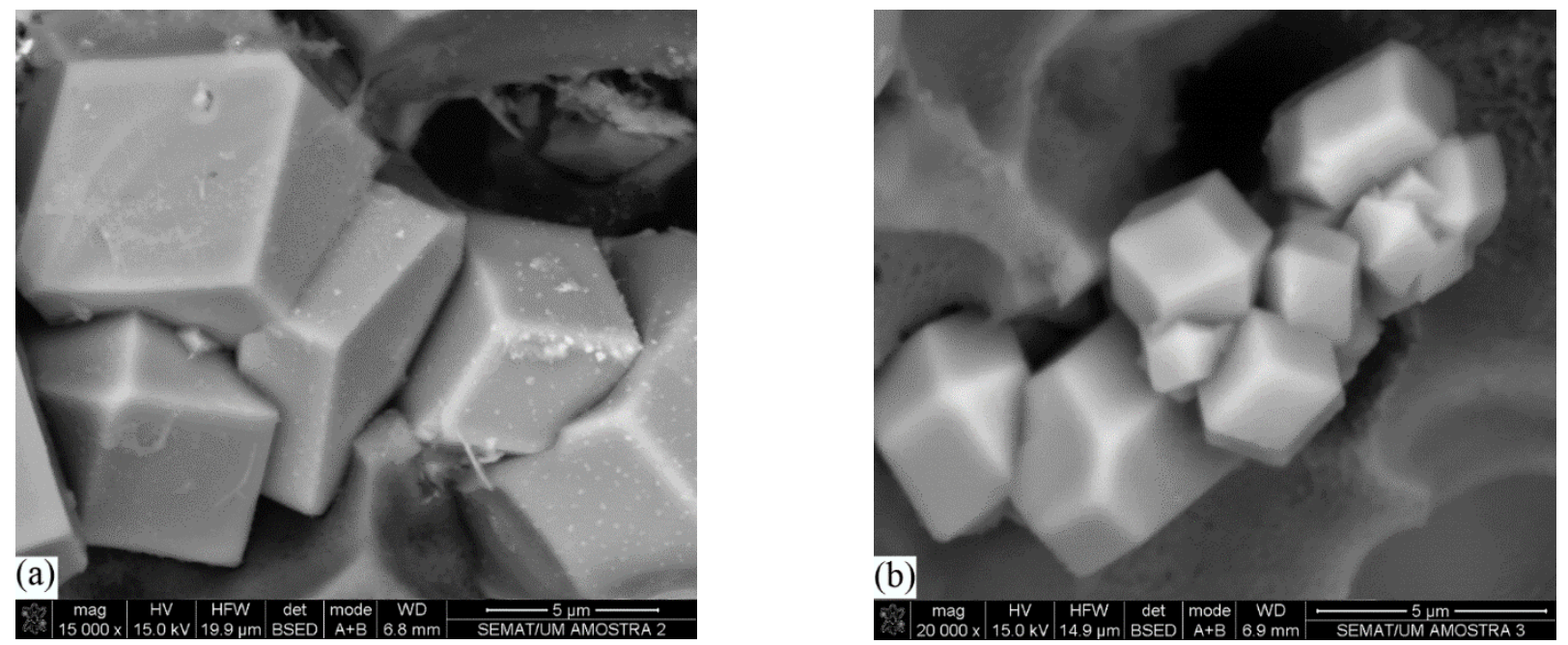

Fig. 11. SEM image of $\alpha-\mathrm{Al}_{17}\left(\mathrm{Fe}_{3.2} \mathrm{Mn}_{0.8}\right) \mathrm{Si}_{2}$ morphology present in the sample US treated until. (a) $618 \pm 2^{\circ} \mathrm{C}$; (b) $580 \pm 2^{\circ} \mathrm{C}$.

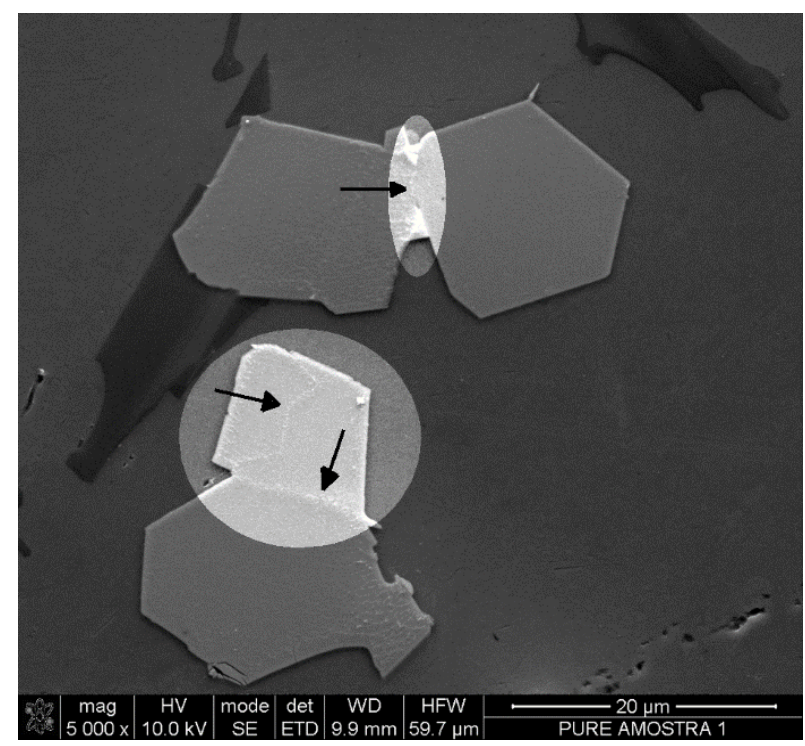

Fig. 12. SEM image of $\alpha-\mathrm{Al}_{17}\left(\mathrm{Fe}_{3.2} \mathrm{Mn}_{0.8}\right) \mathrm{Si}_{2}$ in a sample US treated until $618 \pm 2^{\circ} \mathrm{C}$ showing fracture lines inside the particles. 


\section{Conclusions}

The main conclusions that can be drawn from this work are the following:

(1) The application of ultrasonic treatment to the melt during cooling until the ranges $618 \pm 2^{\circ} \mathrm{C}$ and $580 \pm 2^{\circ} \mathrm{C}$ changes the morphology of primary $\alpha$-Al grains from dendritic to a more globular structure.

(2) US melt treatment changes the morphology of $\alpha$-intermetallic compounds from Chinese script shaped particles to polyhedral crystals and suppress the formation of $\beta$-phase intermetallics. Furthermore, the application of this treatment to the melt also stimulates the homogenization of the solute and temperature field.

(3) US melt treatment induces the formation of polyhedral crystals by increasing the nucleation rate, leading to the occurrence of heterogeneous nucleation, and promotes their posterior fragmentation and dispersion throughout the melt.

(4) The as-cast sample presents $\alpha-\mathrm{Al}_{17}\left(\mathrm{Fe}_{3.2}, \mathrm{Mn}_{0.8}\right) \mathrm{Si}_{2}, \quad \alpha-\mathrm{Al}_{8} \mathrm{Fe}_{2} \mathrm{Si}, \quad \beta-\mathrm{Al}_{9} \mathrm{Fe}_{2} \mathrm{Si}_{2}$ and $\mathrm{Al} 2 \mathrm{Cu}$ intermetallic compounds, while the US treated sample only present the $\alpha-\mathrm{Al}_{17}\left(\mathrm{Fe}_{3.2}, \mathrm{Mn}_{0.8}\right) \mathrm{Si}_{2}$ and $\mathrm{Al}_{2} \mathrm{Cu}$ phases.

(5) The application of acoustic energy to the melt leads to the formation of intermetallic compounds with smaller dimensions than the Chinese script particles that appear in the as-cast sample. The application of ultrasonic treatment until temperatures below solidus promotes the formation of intermetallic compounds with smaller dimensions than those obtained at higher temperatures. 


\section{Acknowledgement}

This research was supported by FCT - Portuguese Foundation for Science and Technology and was developed on the aim of the research project PTDC/EME-TME/119658/2010 and the Post-Doctoral grant SFRH/BPD/76680/2011. Acknowledgements also to the University of Minho, for the provision of research facilities. 


\section{References}

[1] E. Taghaddos, M.M. Hejazi, R. Taghiabadi, S.G. Shabestari, J. Alloys Compound. 468 (2009) 539545.

[2] L. Ceschini, I. Boromei, A. Morri, S. Seifeddine, I.L. Svensson, Mater. Design. 36 (2012) 522-528.

[3] C.L. Chen, R.C. Thomson, J. Alloys Compound. 490 (2010) 293-300.

[4] S. Hegde, K.N. Prabhu, J. Mater. Sci. 43 (2008) 3009-3027.

[5] S.G. Shabestari, M. Ghanbari, J. Alloys Compound. 508 (2010) 315-319.

[6] S.G. Shabestari, M. Keshavarz, M.M. Hejazi, J Alloys Compound. 477 (2009) 892-899.

[7] S. Seifeddine, S. Johansson, I.L. Svensson, Mater. Sci. Eng. A. 490 (2008) 385-390.

[8] K. Liu, X. Cao, X.G. Chen, Metall. Mater. Trans. A. 42 (2011) 2004-2016.

[9] D.N. Miller, L. Lu, A.K. Dahle, Metall. Materi. Trans. B. 37 (2006) 873-878.

[10] S.G. Shabestari, Mater. Sci. Eng. A. 383 (2004) 289-298.

[11] L. Ceschini, I. Boromei, A. Morri, S. Seifeddine, I.L. Svensson, J. Mater. Process. Tech. 209 (2009) 5669-5679.

[12] L.A. Narayanan, F.H. Samuel, J.E. Gruzleski, Metall. Mater. Tran. A. 25 (1994) 1761-1773.

[13] Z. Ma, A.M. Samuel, F.H. Samuel, H.W. Doty, S. Valtierra, Mater. Sci. Eng. A. 490 (2008) 36-51.

[14] L. Lu, A.K. Dahle, Metall. Mater. Trans. A. 36 (2005) 819-835.

[15] S.G. Shabestari, E. Parshizfard, J. Alloys Compound. 509 (2011) 7973-7978.

[16] W. Khalifa, Y. Tsunekawa, M. Okumiya, J. Mater. Process. Tech. 210 (2010) 2178-2187.

[17] C.M. Dinnis, J.A. Taylor, A.K. Dahle, Scripta Mater. 53 (2005) 955-958.

[18] M.V. Kral, Mater. Lett. 59 (2005) 2271-2276.

[19] G. Zhong, S. Wu, H. Jiang, P. An, J. Alloys Compound. 492 (2010) 482-487.

[20] H. Puga, J. Barbosa, D. Soares, F. Silva, S. Ribeiro, J. Mater. Process. Tech. 209 (2009) 5195-5203.

[21] H. Puga, J. Barbosa, S. Costa, S. Ribeiro, A.M.P. Pinto, M. Prokic, Mater. Sci. Eng. A. 560 (2013) 589-595.

[22] H. Puga, S. Costa, J. Barbosa, S. Ribeiro, M. Prokic, J. Mater. Process. Techn. 211 (2011) 17291735.

[23] A. Das, H. R. Kotadia, Mater Chem Phys. 125 (2011) 853-859.

[24] G. I. Eskin, Ultrasonic Treatment of Light Alloy Melts, $1^{\text {th }}$ ed. Amsterdam: Netherlands, 1998.

[25] S. Ji, W. Yang, F. Gao, D. Watson, Z. Fan, Mater. Sci. Eng. A. 564 (2013) 130-139.

[26] V. Hansen, B. Hauback, M. Sundberg, C. Rømming, J. Gjønnes, 54 (1998) 351-357.

[27] J. Roger, F. Bosselet, J.C. Viala, J. Solid State Chem. 184 (2011) 1120-1128.

[28] L. Backerud, G. Chai, J. Tamminen, Solidification Characteristics of Aluminum Alloys, Vol 2: Foundry Alloys, AFS: Stokholm, 1990.

[29] K. Nogita, A.K. Dahle, Mater. Charact. 46 (2001) 305-310.

[30] S. Shankar, Y.W. Riddle, M.M. Makhlouf, Acta Mater. 52 (2004) 4447-4460.

[31] E. Tillová, M. Chalupová, L. Hurtalová, M. Bonek, L.A. Dobrzański, J. Ach. Mater. Manuf. Eng. 47 (2011) 19-25.

[32] S. Gowri, F.H. Samuel, Metall. Mater. Trans. A. 25A (1994) 437-448. 
Table 1. Composition of the AlSi9Cu3 alloy used in this work.

\begin{tabular}{c|c|c|c|c|c|c|c}
\hline Element & Si & $\mathbf{F e}$ & $\mathbf{M g}$ & $\mathbf{C u}$ & $\mathbf{M n}$ & $\mathbf{Z n}$ & $\mathbf{A l}$ \\
\hline $\mathbf{W t \%}$ & 9.15 & 0.66 & 0.18 & 2.25 & 0.26 & 0.47 & Bal. \\
\hline
\end{tabular}


Table 2 - Chemical composition of intermetallic phases detected on the as-cast AlSi9Cu3 alloy produced without treatment with acoustic energy, corresponding to phases Z1, Z2 and Z3 indicated in Fig. 3.

\begin{tabular}{c|c|c|c|c|c}
\hline \multirow{2}{*}{ Constituent } & \multicolumn{5}{|c}{ Composition (at \%) } \\
\cline { 2 - 6 } & $\mathrm{Al}$ & $\mathrm{Si}$ & $\mathrm{Fe}$ & $\mathrm{Cu}$ & $\mathrm{Mn}$ \\
\hline $\mathrm{Z} 1$ & 69.8 & 13.3 & 14.9 & - & - \\
\hline $\mathrm{Z} 2$ & 71.8 & 11.7 & 11.6 & - & 4.5 \\
\hline $\mathrm{Z} 3$ & 53.2 & - & - & 46.8 & - \\
\hline
\end{tabular}


Table 3 - Chemical composition of intermetallic phases detected on the samples US treated until $580^{\circ} \mathrm{C}$, corresponding to phases Z2 and Z3 indicated in Fig. 7 (b).

\begin{tabular}{c|c|c|c|c|c}
\hline \multirow{2}{*}{ Constituent } & \multicolumn{5}{|c}{ Composition (at \%) } \\
\cline { 2 - 6 } & $\mathrm{Al}$ & $\mathrm{Si}$ & $\mathrm{Fe}$ & $\mathrm{Cu}$ & $\mathrm{Mn}$ \\
\hline $\mathrm{Z} 2$ & 74.4 & 12.6 & 9.5 & - & 3.5 \\
\hline $\mathrm{Z} 3$ & 57.3 & - & - & 42.7 & - \\
\hline
\end{tabular}


Table 1. Composition of the AlSi9Cu3 alloy used in this work.

Table 2 - Chemical composition of intermetallic phases detected on the as-cast AlSi9Cu3 alloy produced without treatment with acoustic energy, corresponding to phases Z1, Z2 and Z3 indicated in Fig. 3.

Table 3 - Chemical composition of intermetallic phases detected on the samples US treated until $580^{\circ} \mathrm{C}$, corresponding to phases $\mathrm{Z} 2$ and $\mathrm{Z} 3$ indicated in Fig. 7 (b). 
Click here to download high resolution image

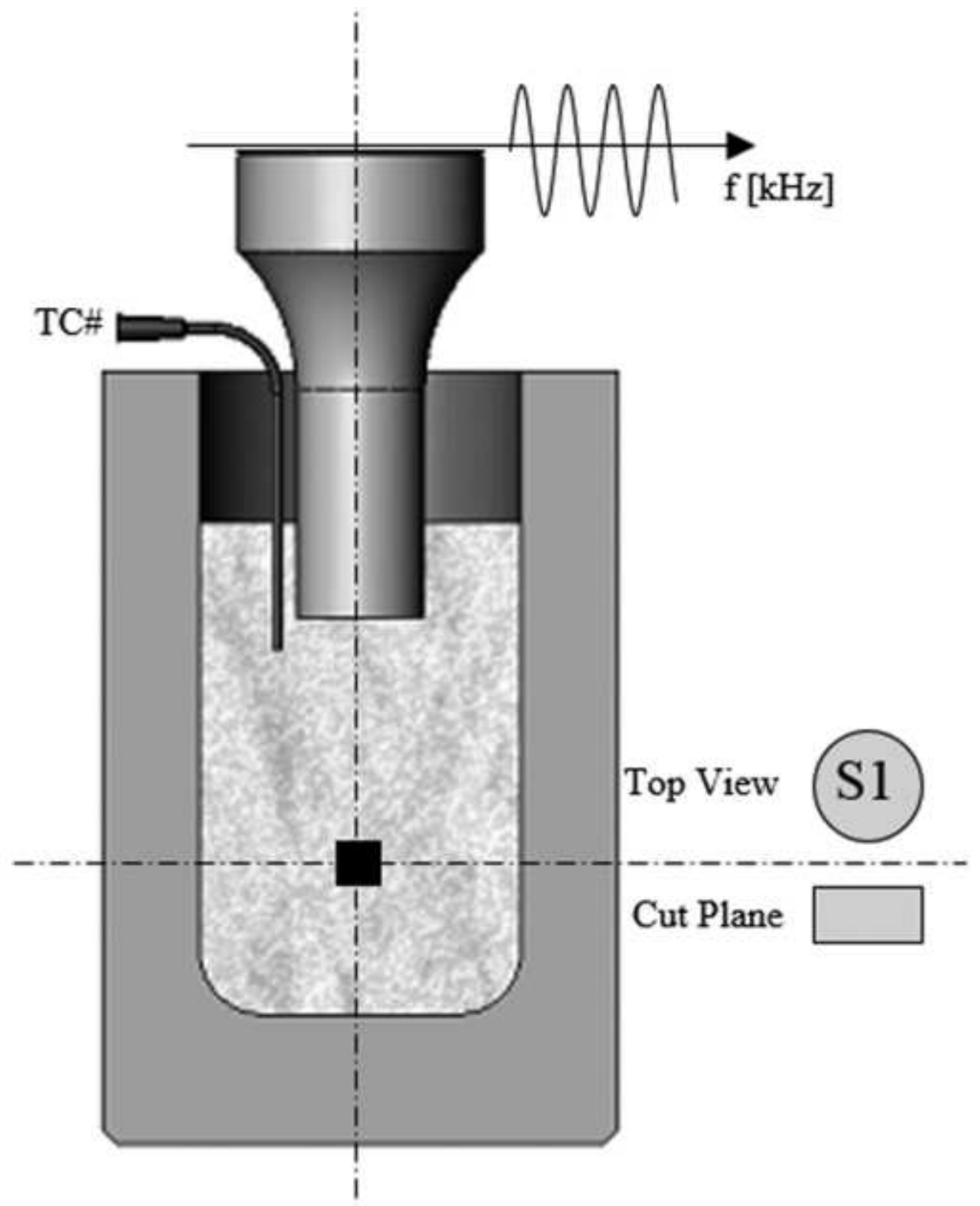


Click here to download high resolution image

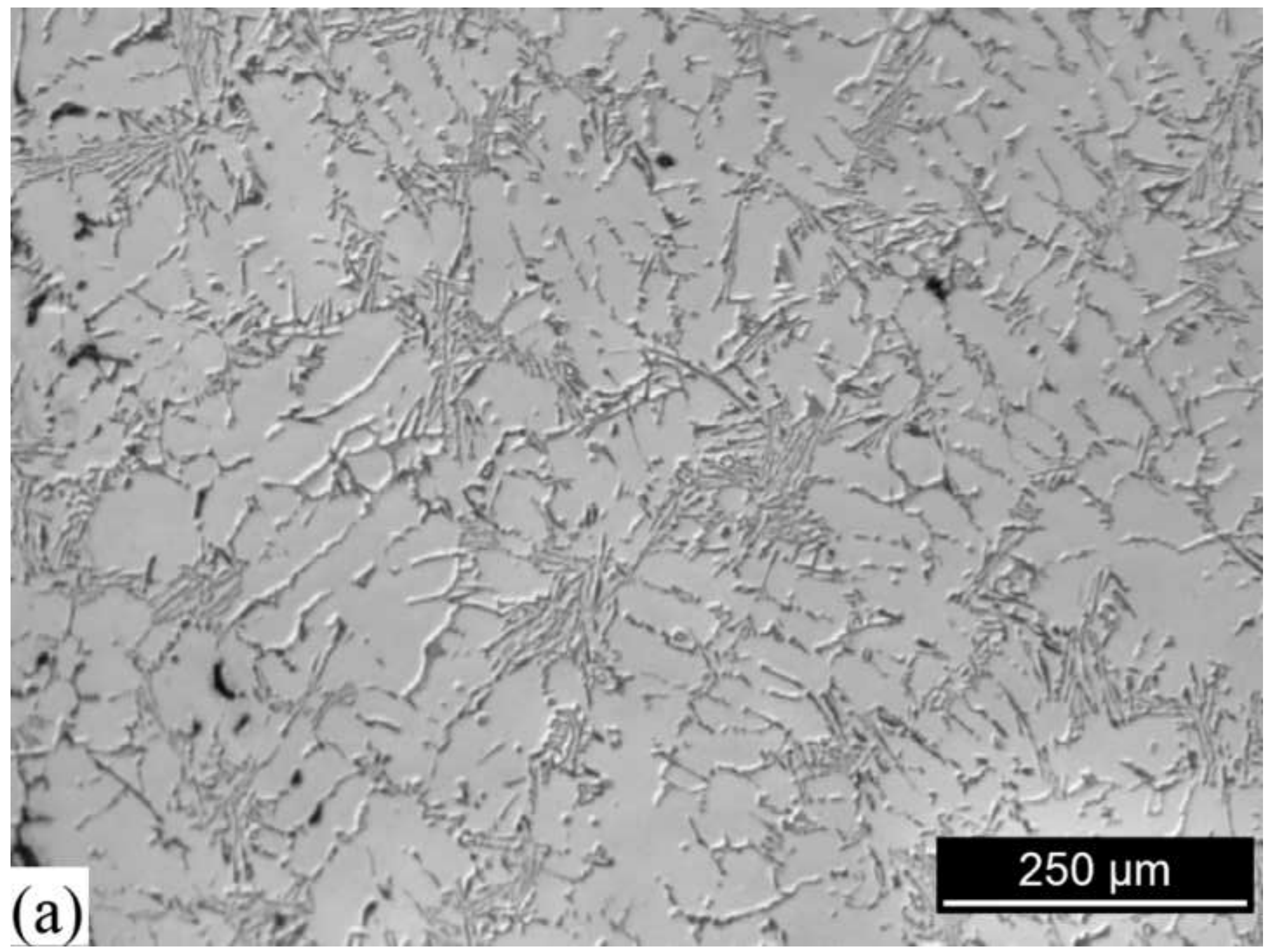




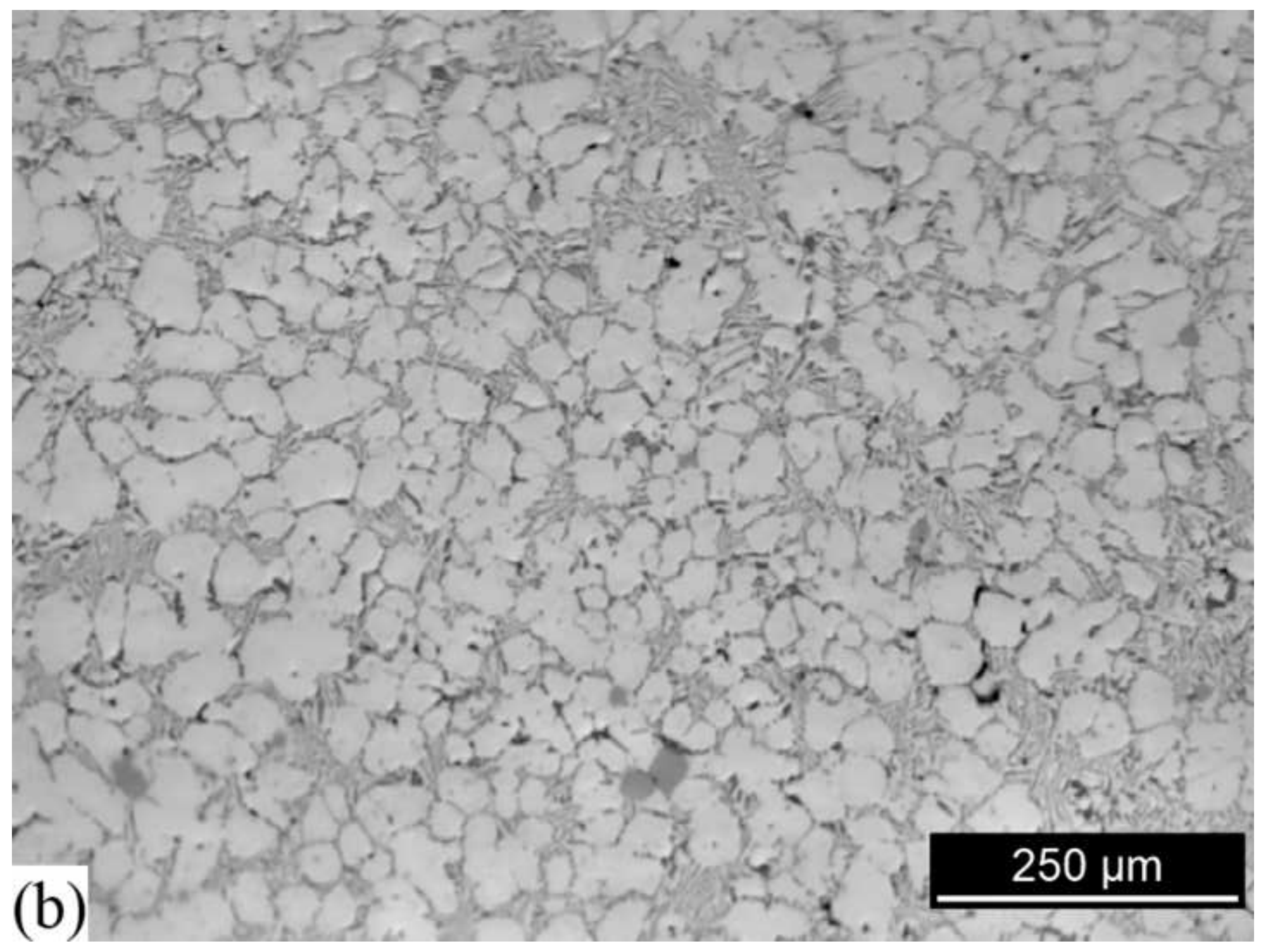

$$
\text { . }
$$

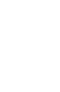

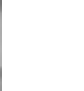$$
\text { . }
$$$$
\text { . }
$$

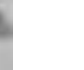

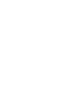




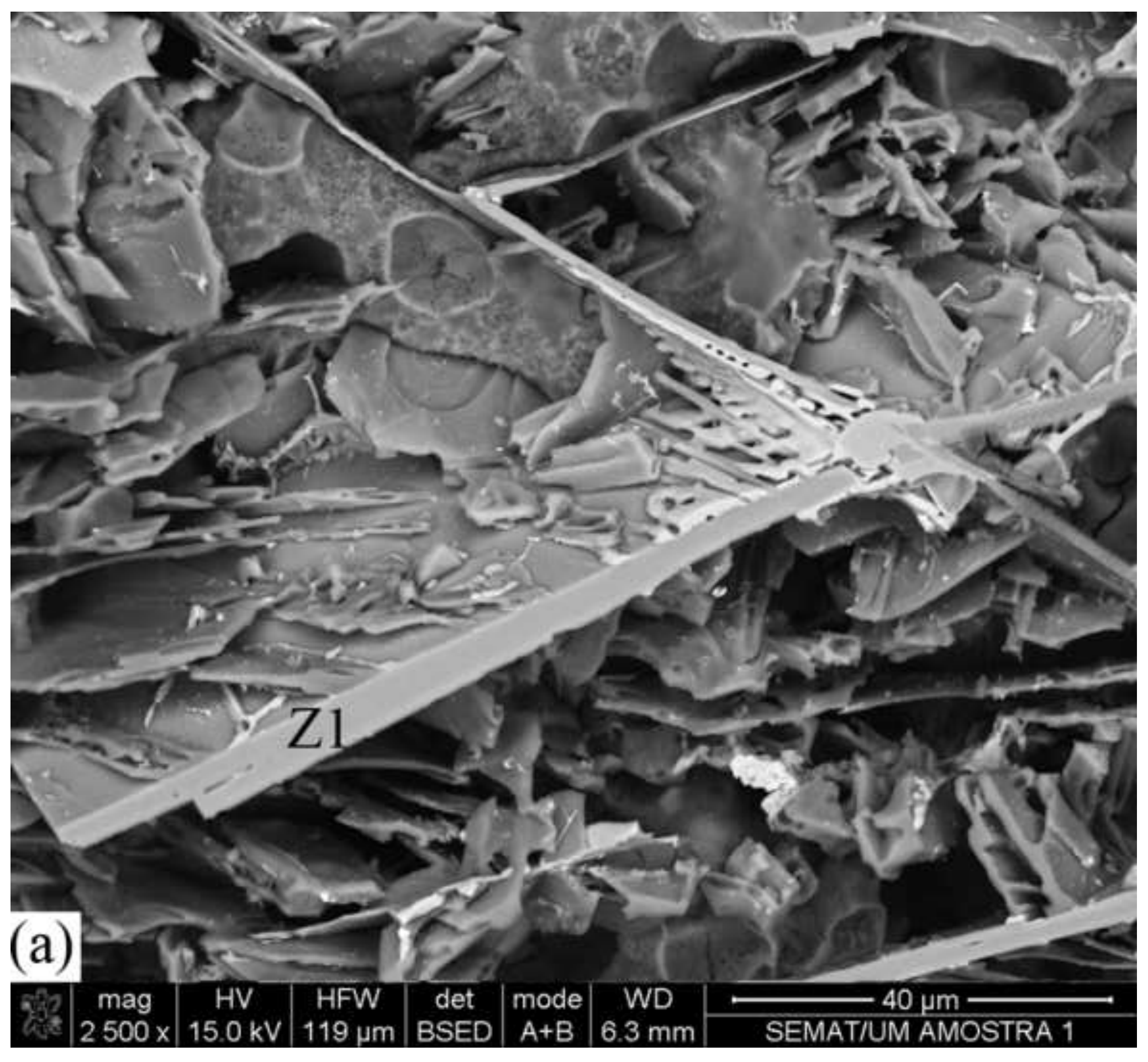

(a)

mag

HV $119 \mu \mathrm{m}$ BSED A+B $6.3 \mathrm{~mm}$ 


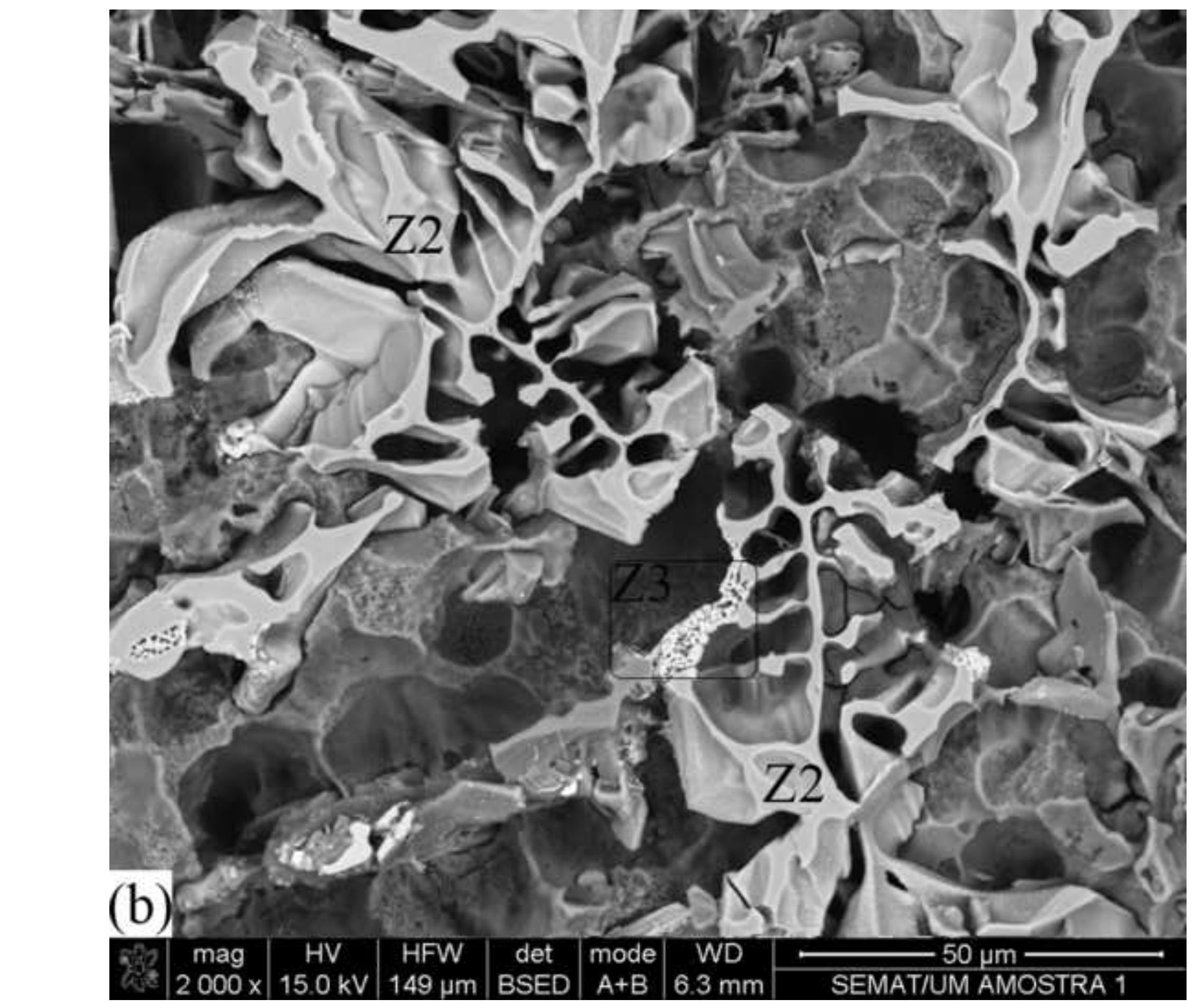

Fig. $3(b)$
Click here to download high resolution image

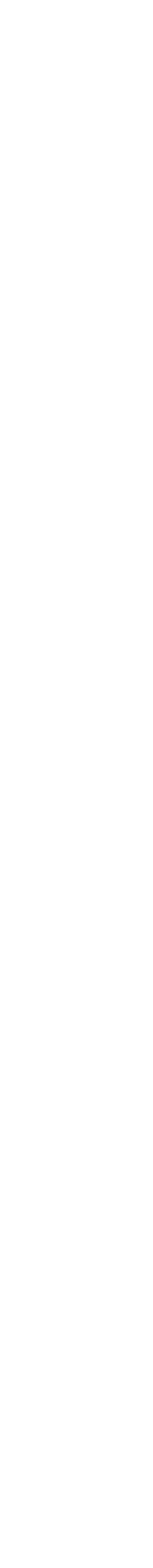




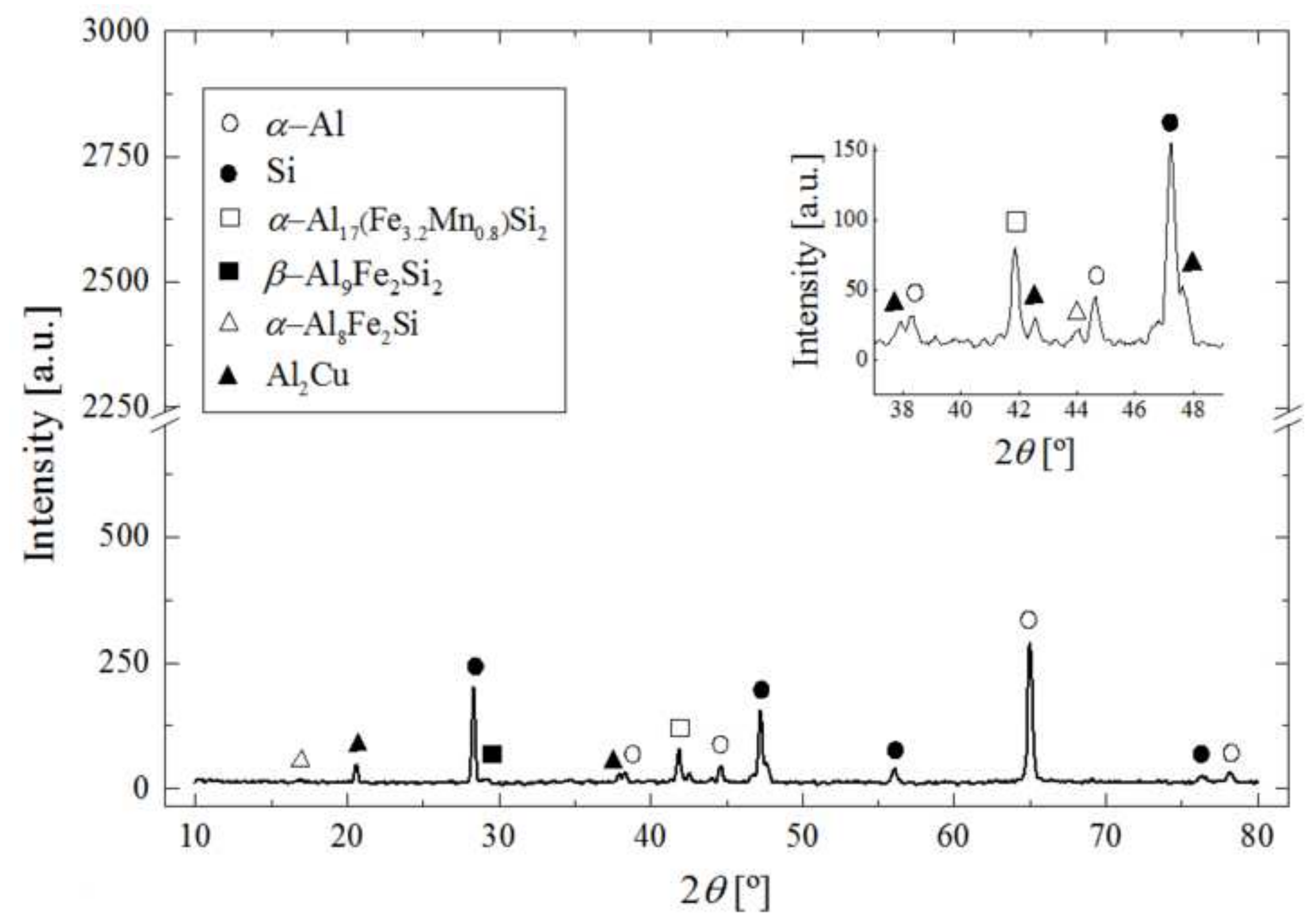


Click here to download high resolution image

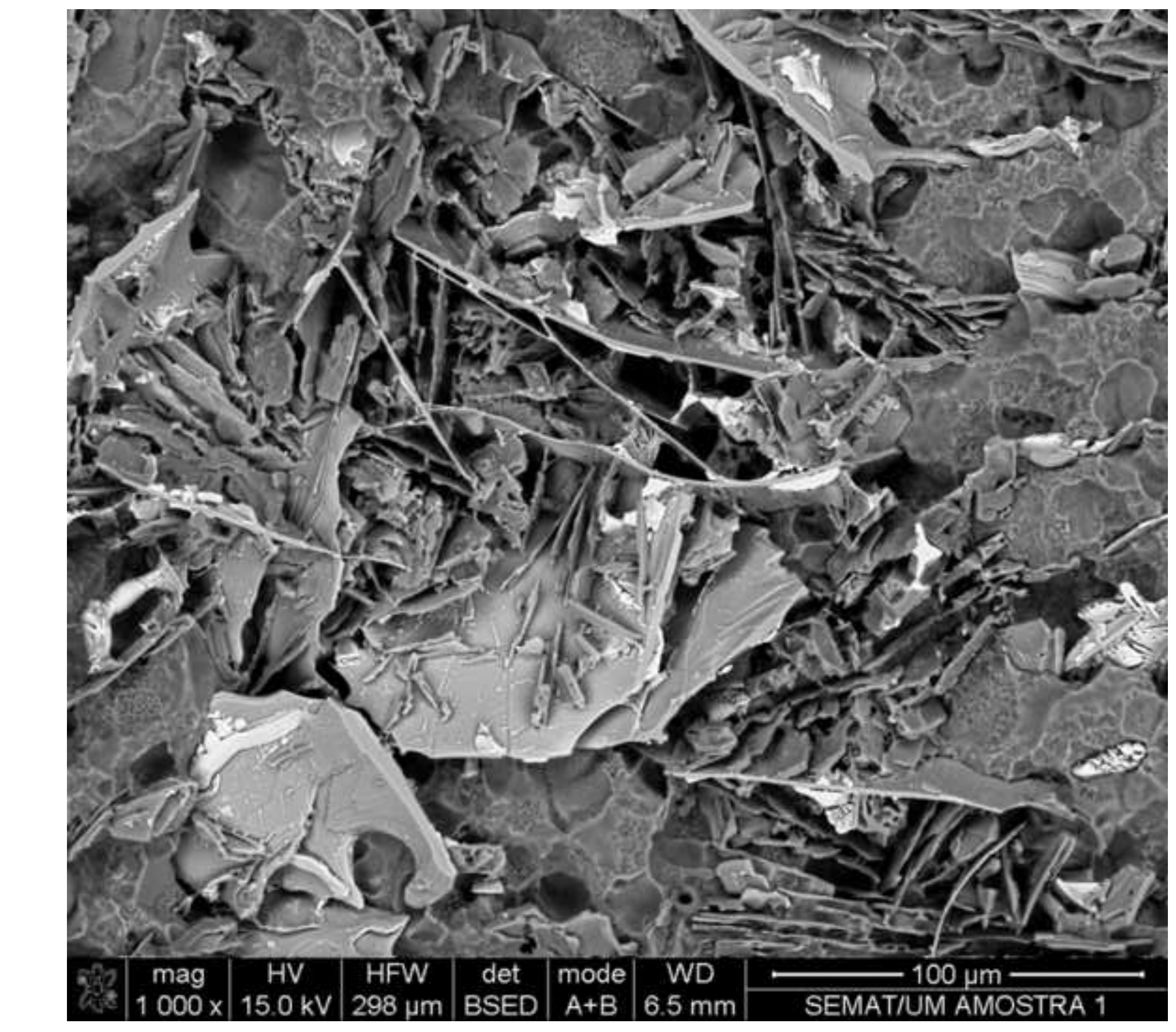


Fig. 6
Click here to download high resolution image

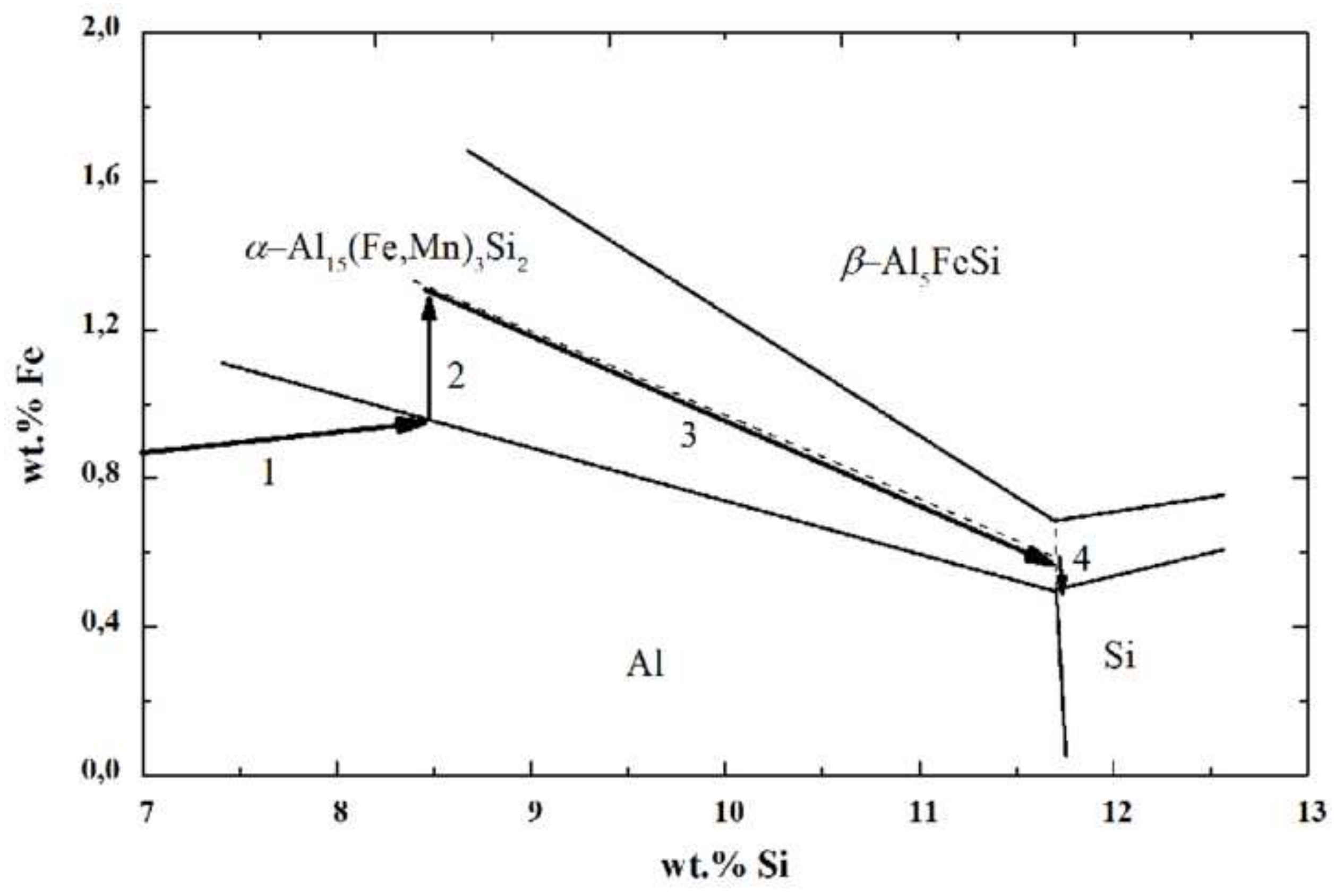


Click here to download high resolution image

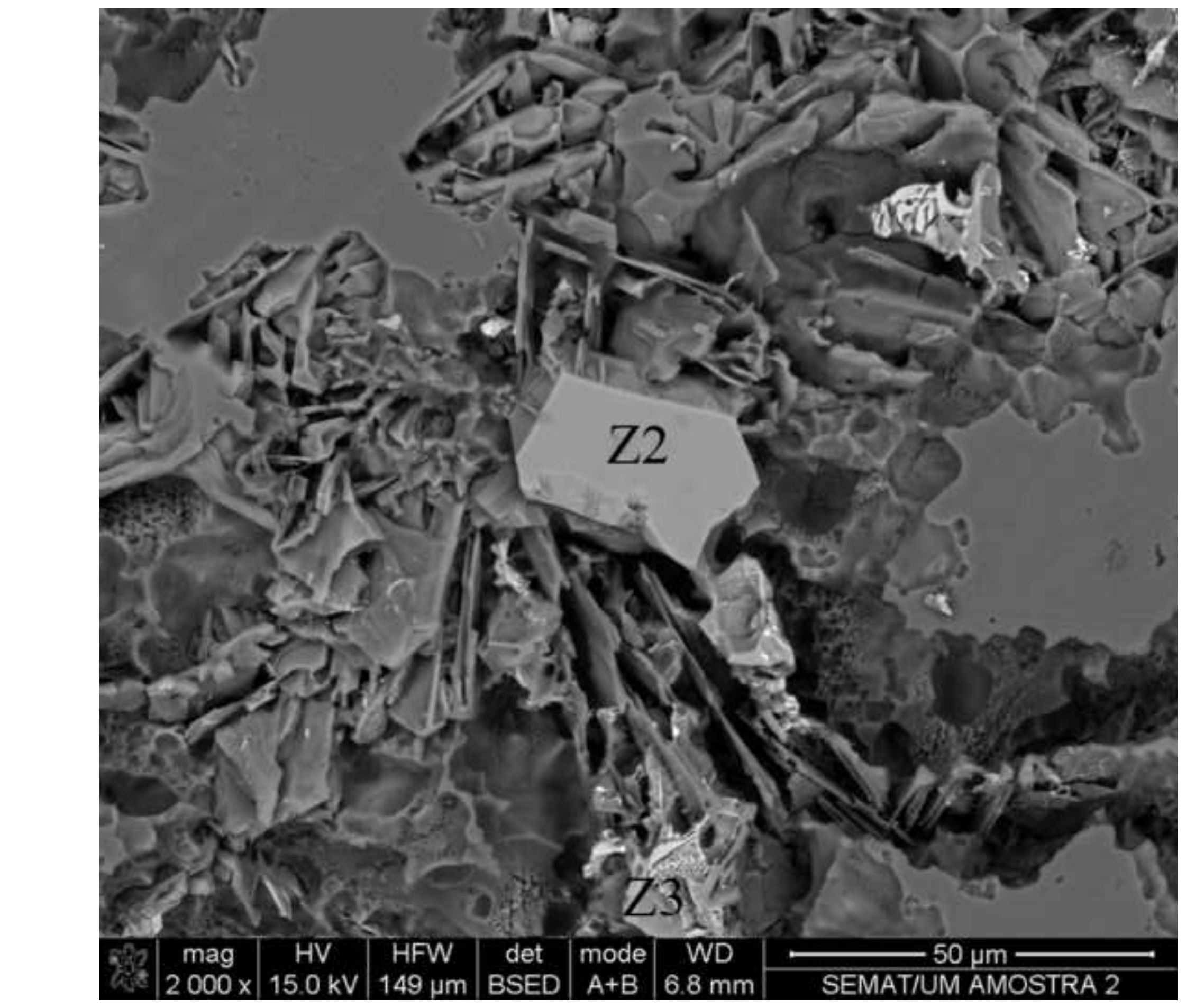

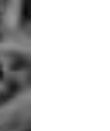

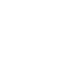




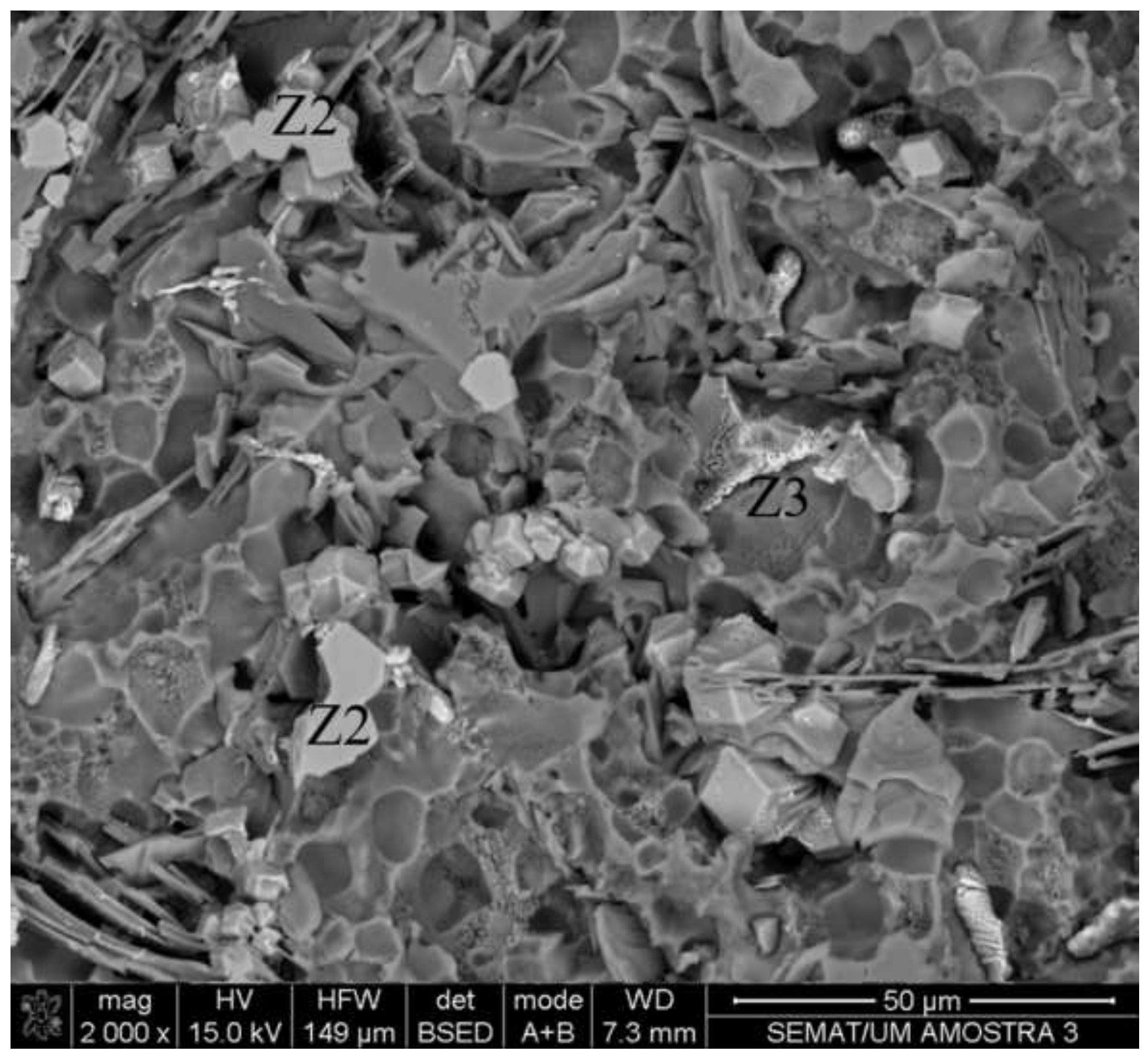

Fig. $7(b)$
Click here to download high resolution image

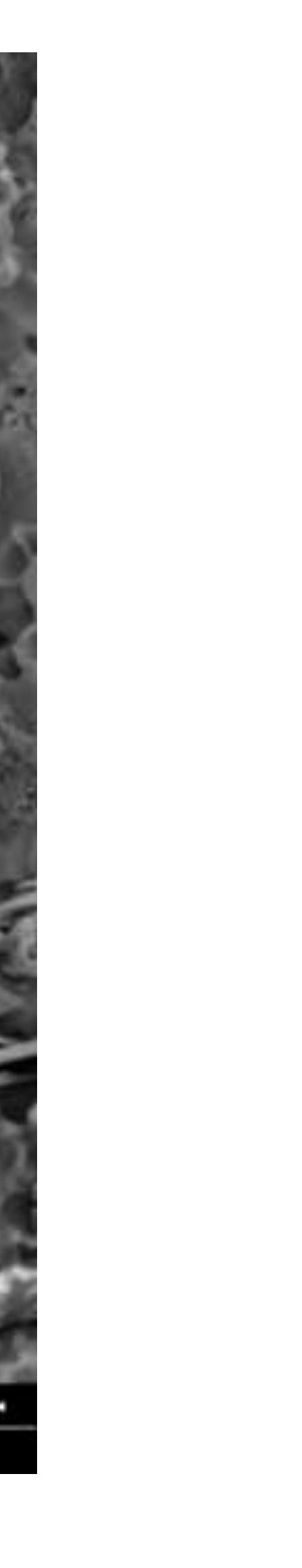

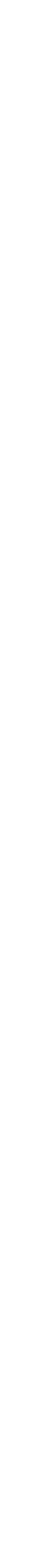




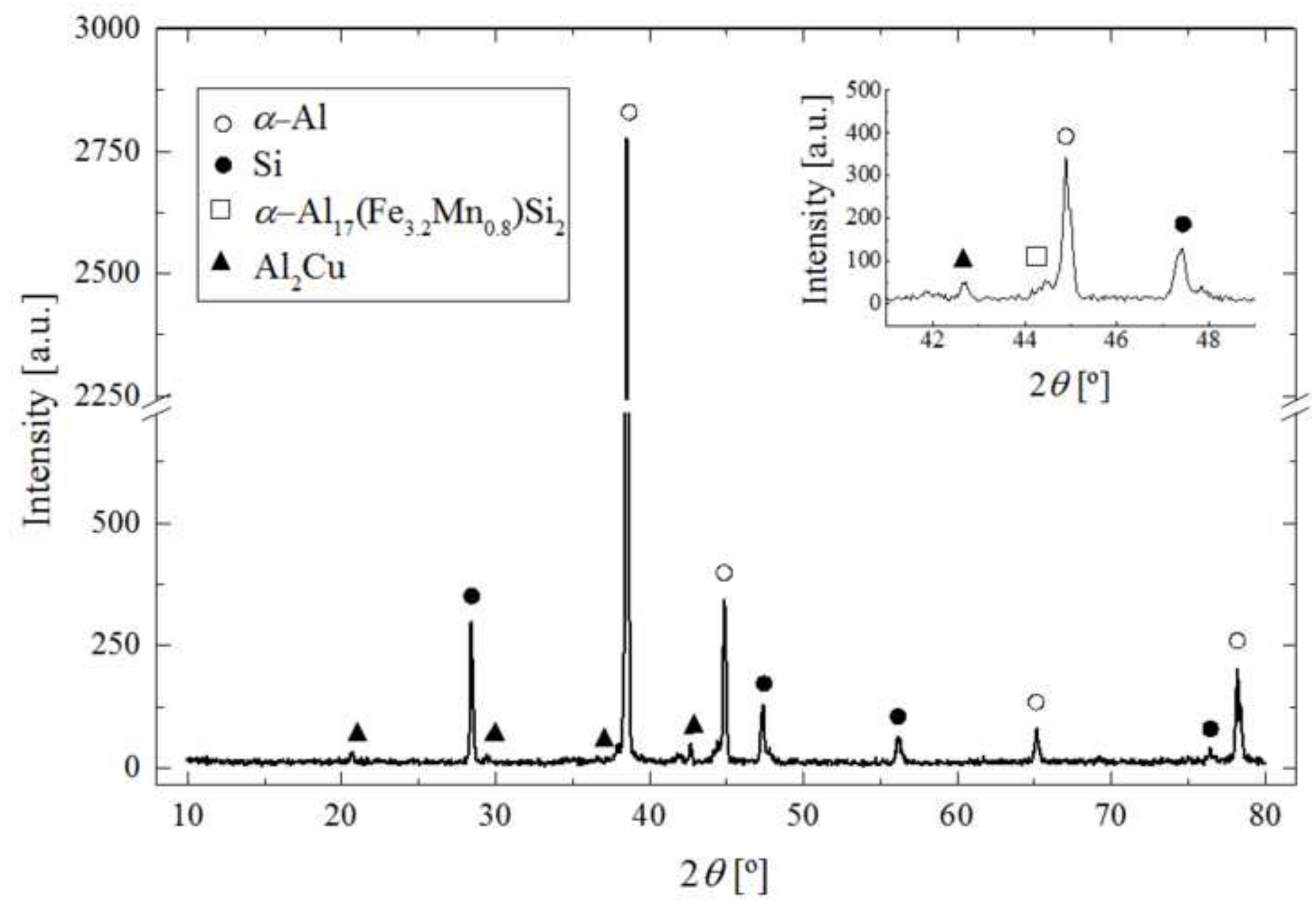


Click here to download high resolution image

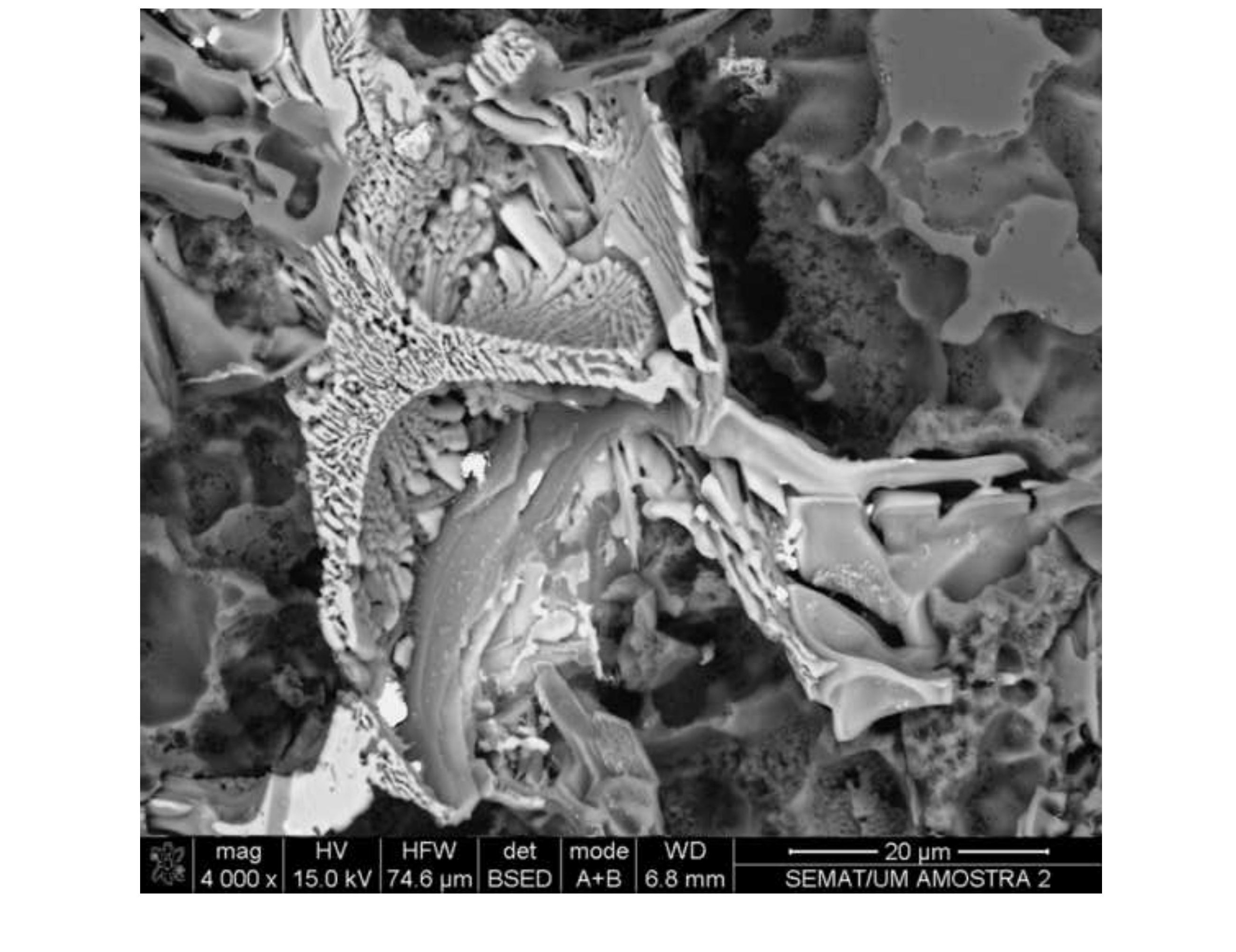

Fig. 10

\footnotetext{
ere
}

high resolution imag

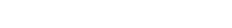
. 
Click here to download high resolution image

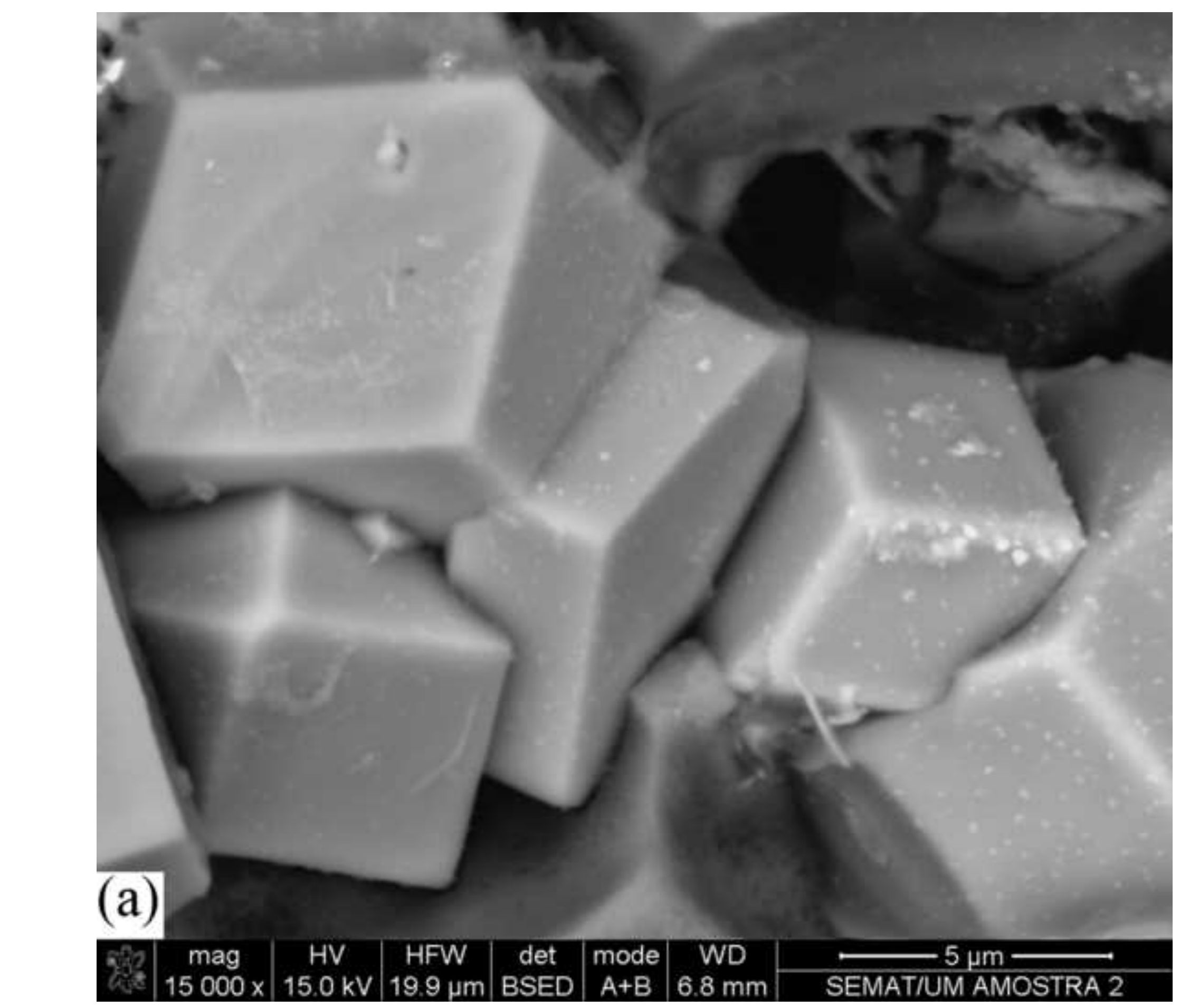

$15000 \times 15.0 \mathrm{kV} 19.9 \mu \mathrm{m}$ BSED $\mathrm{A}+\mathrm{B} 6.8 \mathrm{~mm}$ SEMAT/UM AMOSTRA 2




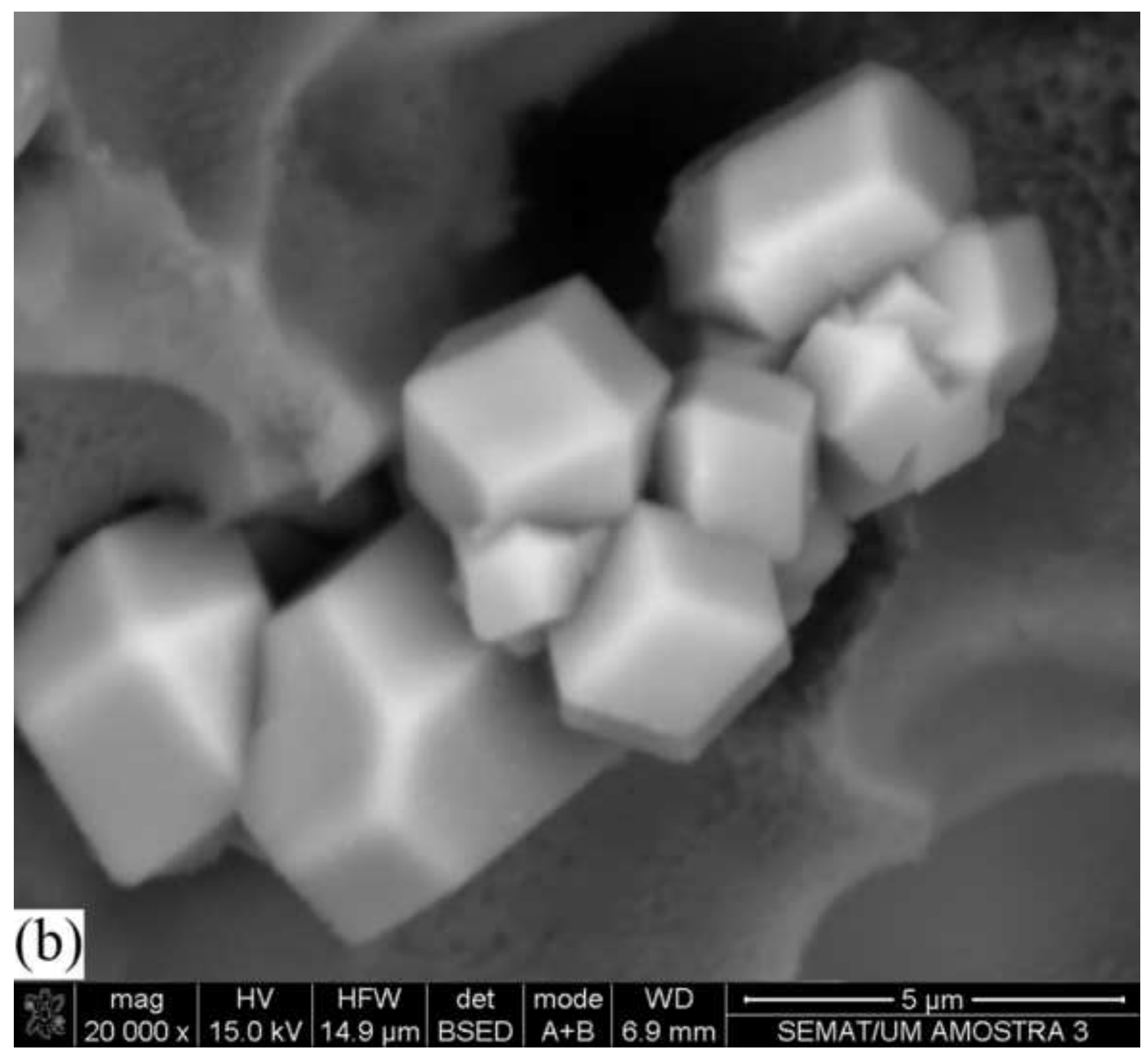

Fig. $11(b)$
Click here to download high resolution image

(b)

$20000 \times 15.0 \mathrm{kV} 14.9 \mu \mathrm{m}$ BSED $\mathrm{A}+\mathrm{B} 6.9 \mathrm{~mm}$

SEMAT/UM AMOSTRA 3 


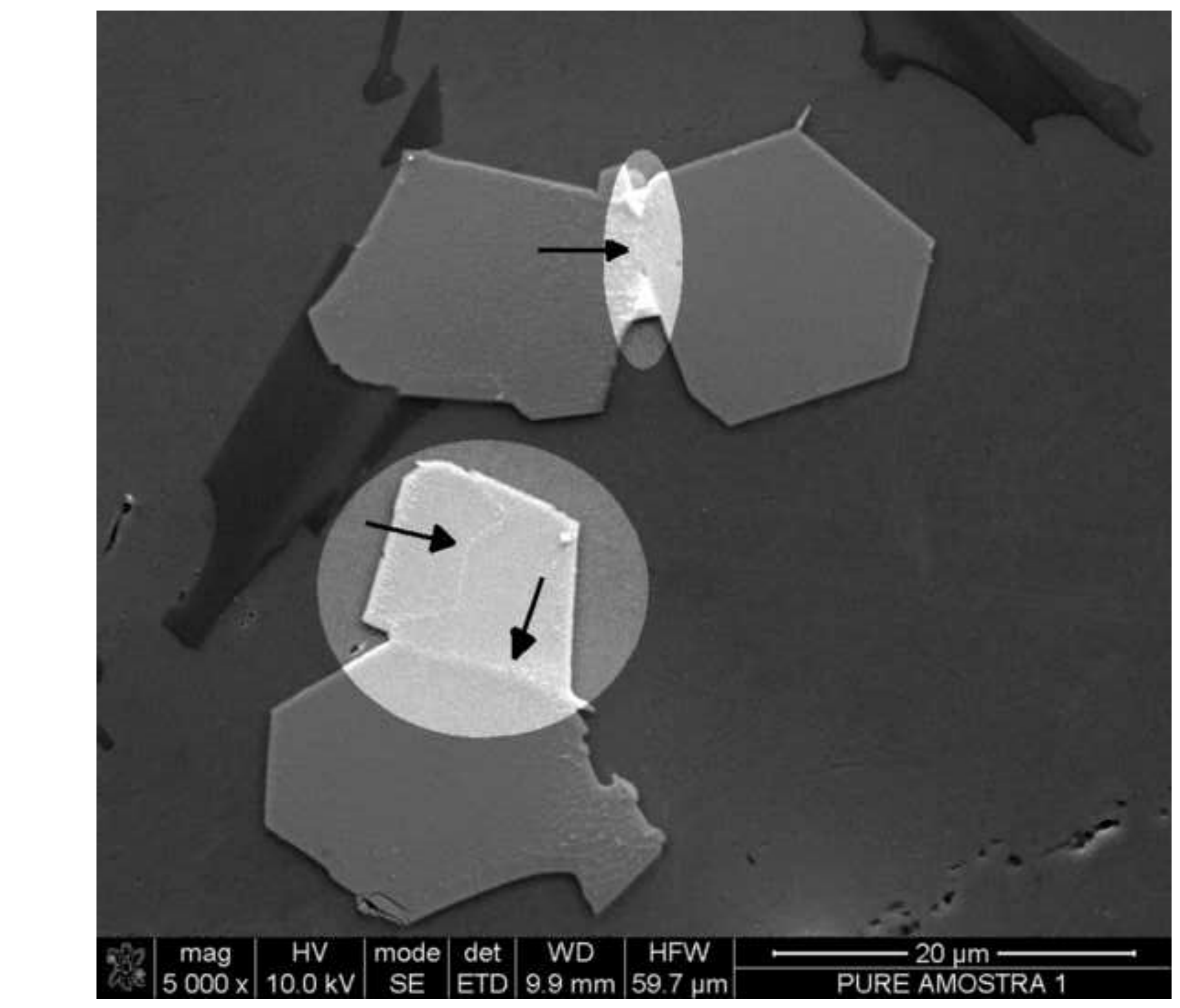


Click here to download high resolution image

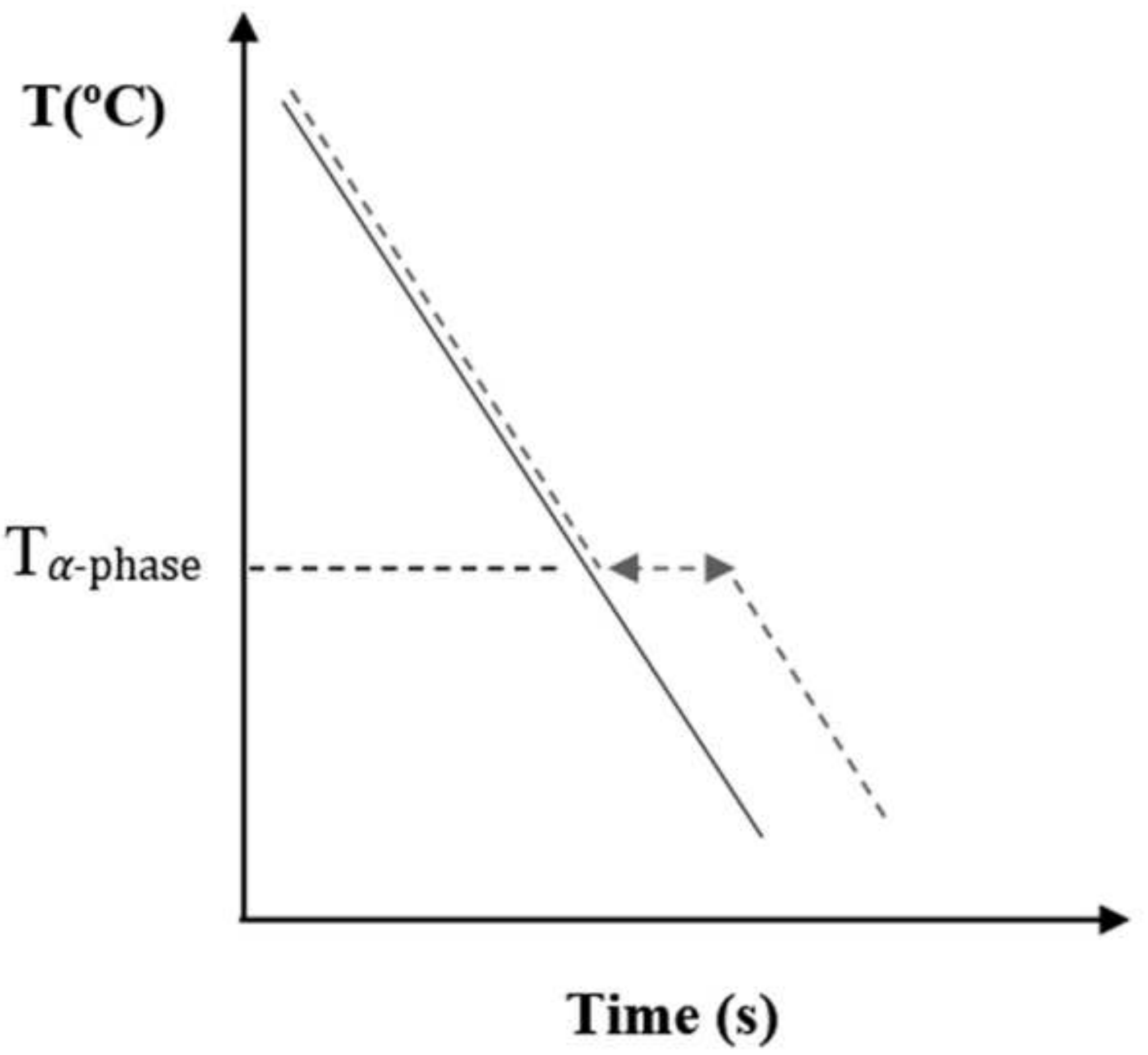

\section{Time (s)}


Fig. 1. Schematic representation of the experimental setup used in the experiments and position of the analysed section on the sample.

Fig. 2. Optical micrographs for $\mathrm{AlSi}_{9} \mathrm{Cu}_{3}(\mathrm{Fe})$ samples obtained in a steel mould, preheated at $250^{\circ} \mathrm{C}$, in different processing conditions. (a) As-cast sample; (b) Sample US treated until $618 \pm 2^{\circ} \mathrm{C}$.

Fig. 3. SEM image of deeply etched samples showing the morphology of complex intermetallic compounds present in as-cast sample. (a) Platelet like intermetallics (Z1); (b) Chinese script like intermetallics (Z2) and eutectic $\mathrm{Al}_{2} \mathrm{Cu}(\mathrm{Z} 3)$.

Fig. 4. X-ray diffraction spectrum of the sample obtained without US treatment, revealing the co-existence of $\alpha$-Al, $\mathrm{Si}, \mathrm{Al}_{17}\left(\mathrm{Fe}_{3.2}, \mathrm{Mn}_{0.8}\right) \mathrm{Si}_{2}, \alpha-\mathrm{Al}_{8} \mathrm{Fe}_{2} \mathrm{Si}, \beta-\mathrm{Al}_{9} \mathrm{Fe}_{2} \mathrm{Si}_{2}$ and $\mathrm{Al}_{2} \mathrm{Cu}$ phases.

Fig. 5. SEM image of $\beta$-phase platelets and Chinese script shaped $\alpha$-phase, showing that $\beta$-platelets continue to growth even after an intersection point occurred.

Fig. 6. Scheme of solidification process of an Al-Si-Cu alloy with 0.25\%wt. Mn [28].

Fig. 7. SEM image showing the morphology of intermetallic compounds present in the sample US treated until (a) $618 \pm 2^{\circ} \mathrm{C}$ and (b) $580 \pm 2^{\circ} \mathrm{C}$

Fig. 8. EDS spectrum of the hexagonal shaped intermetallic compound present in the non US treated sample (identified as Z2 in Fig. 3 (b)) and in that US treated until $580^{\circ} \mathrm{C}$ (identified as Z2 in Fig. 7 (b)), suggesting that they are, in fact, the same phase.

Fig. 9. X-ray diffraction spectrum of the sample US treated until $580^{\circ} \mathrm{C}$, revealing the co-existence of $\alpha$ - $\mathrm{Al}, \mathrm{Si}, \mathrm{Al}_{17}\left(\mathrm{Fe}_{3.2}, \mathrm{Mn}_{0.8}\right) \mathrm{Si}_{2}$ and $\mathrm{Al}_{2} \mathrm{Cu}$ phases.

Fig. 10. SEM image of $\mathrm{Al}_{2} \mathrm{Cu}$ phase in the sample US treated until $618 \pm 2{ }^{\circ} \mathrm{C}$.

Fig. 11. SEM image of $\alpha-\mathrm{Al}_{17}\left(\mathrm{Fe}_{3.2} \mathrm{Mn}_{0.8}\right) \mathrm{Si}_{2}$ morphology present in the sample US treated until. (a) $618 \pm 2^{\circ} \mathrm{C}$; (b) $580 \pm 2^{\circ} \mathrm{C}$.

Fig. 12. SEM image of $\alpha-\mathrm{Al}_{17}\left(\mathrm{Fe}_{3.2} \mathrm{Mn}_{0.8}\right) \mathrm{Si}_{2}$ in a sample US treated until $618 \pm 2^{\circ} \mathrm{C}$ showing fracture lines inside the particles.

Fig. 13. Schematic representation of the mechanism of application of ultrasonic vibrations to improve the intermetallics fragmentation phenomenon. 